Atmos. Chem. Phys., 20, 14669-14693, 2020

https://doi.org/10.5194/acp-20-14669-2020

(C) Author(s) 2020. This work is distributed under

the Creative Commons Attribution 4.0 License.

\title{
Role of equatorial waves and convective gravity waves in the 2015/16 quasi-biennial oscillation disruption
}

\author{
Min-Jee Kang ${ }^{1}$, Hye-Yeong Chun ${ }^{1}$, and Rolando R. Garcia ${ }^{2}$ \\ ${ }^{1}$ Department of Atmospheric Sciences, Yonsei University, Seoul, South Korea \\ ${ }^{2}$ National Center for Atmospheric Research, Boulder, Colorado, USA \\ Correspondence: Hye-Yeong Chun (chunhy@yonsei.ac.kr) and Min-Jee Kang (kangmj@yonsei.ac.kr)
}

Received: 29 July 2020 - Discussion started: 17 August 2020

Revised: 13 October 2020 - Accepted: 26 October 2020 - Published: 2 December 2020

\begin{abstract}
In February 2016, the descent of the westerly phase of the quasi-biennial oscillation $(\mathrm{QBO})$ was unprecedentedly disrupted by the development of easterly winds. Previous studies have shown that extratropical Rossby waves propagating into the deep tropics were the major cause of the 2015/16 QBO disruption. However, a large portion of the negative momentum forcing associated with the disruption still stems from equatorial planetary and small-scale gravity waves, which calls for detailed analyses by separating each wave mode compared with climatological QBO cases. Here, the contributions of resolved equatorial planetary waves (Kelvin, Rossby, mixed Rossby-gravity (MRG), and inertia-gravity (IG) waves) and small-scale convective gravity waves (CGWs) obtained from an offline CGW parameterization to the 2015/16 QBO disruption are investigated using MERRA-2 global reanalysis data from October 2015 to February 2016. In October and November 2015, anomalously strong negative forcing by MRG and IG waves weakened the QBO jet at $0-5^{\circ} \mathrm{S}$ near $40 \mathrm{hPa}$, leading to Rossby wave breaking at the QBO jet core in the Southern Hemisphere. From December 2015 to January 2016, exceptionally strong Rossby waves propagating horizontally (vertically) continuously decelerated the southern (northern) flank of the jet. In February 2016, when the westward CGW momentum flux at the source level was much stronger than its climatology, CGWs began to exert considerable negative forcing at $40-50 \mathrm{hPa}$ near the Equator, in addition to the Rossby waves. The enhancement of the negative wave forcing in the tropics stems mostly from strong wave activity in the troposphere associated with increased convective activity and the strong westerlies (or weaker easterlies) in the troposphere, except that the MRG wave forcing is more likely
\end{abstract}

associated with increased barotropic instability in the lower stratosphere.

\section{Introduction}

The quasi-biennial oscillation (QBO) is the dominant source of variability in the equatorial stratosphere, characterized by alternating easterly and westerly winds with a period of around 28 months (Baldwin et al., 2001). Based on the classical theory, the QBO is generated by momentum deposition by vertically propagating equatorial planetary and gravity waves (Lindzen and Holton, 1968; Holton and Lindzen, 1972). The impact of the QBO is not limited to the tropical stratosphere; the QBO modulates the strength of tropospheric convection (Collimore et al., 2003; Liess and Geller, 2012; Lee et al., 2019), Madden-Julian oscillation (Yoo and Son, 2016; Marshall et al., 2017), and the tropical cyclone tracks (Ho et al., 2009). In addition, the QBO affects not only the subtropical jet and the subsequent changes in the growth and life cycle of the synoptic- to planetary-scale waves in the troposphere (Garfinkel and Hartmann, 2011), but also the intensity of the stratospheric polar vortex (Holton and Tan, 1980; Anstey and Shepherd, 2014), which is strongly tied to the surface temperature and pressure distribution in the extratropics (Baldwin and Dunkerton, 2001; Kidston et al., 2015; Gray et al., 2018). The meridional circulation induced by the QBO also changes the transport of chemical species such as ozone (Randel and Wu, 1996), water vapor (Giorgetta and Bengtsson, 1999), and methane (Patra et al., 2003). Therefore, understanding the QBO is important for improving short- and long-range forecasts due to its quasi-periodical 
nature and global impact (Boer and Hamilton, 2008; Scaife et al., 2014).

In February 2016, the sudden development of easterly winds in the middle of the westerly phase of the QBO $(40 \mathrm{hPa})$ interrupted the normal descent of the westerly phase, which was the first such occurrence since QBO observations started in 1953 (Osprey et al., 2016; Newman et al., 2016). This phenomenon is called the $2015 / 16$ QBO disruption. None of the seasonal forecast models predicted the QBO disruption (Osprey et al., 2016), and reproducing the QBO disruption was possible only with the JAGUAR (Japanese Atmospheric General circulation model for Upper Atmosphere Research; Watanabe and Miyahara, 2009) model initialized in January 2016 (Watanabe et al., 2018). A series of studies have shown that the major cause of the QBO disruption was strong equatorward-propagating Rossby waves from the extratropics. Those studies suggested that extratropical Rossby wave generation was enhanced due to a strong El Niño (Dunkerton, 2016; Coy et al., 2017) and low Arctic sea-ice concentration (Hirota et al., 2018). Furthermore, anomalous westerlies in the subtropical lower stratosphere, possibly caused by El Niño and the seasonal timing (Barton and McCormack, 2017), enabled the Rossby wave flux to refract toward the equatorial stratosphere.

However, there have been several cases in which the QBO disruption did not occur despite the presence of westerly winds in the subtropical lower stratosphere and strong Rossby wave flux propagating into the Equator from the Northern Hemisphere (NH) extratropics (e.g., cases in 2010/11). This is consistent with the fact that extratropical Rossby waves generally decelerate the edge of the QBO jet, not the jet core (O'Sullivan, 1997). Thus, it is unclear how the Rossby waves decelerated the QBO jet core during the 2015/16 QBO disruption. Regarding this question, Lin et al. (2019) have shown that strong extratropical waves in a confined longitude region could make a local critical layer for the Rossby waves to break in the middle of the QBO jet. They also argued that high-frequency waves, mainly mixed Rossby-gravity (MRG) waves, slowed down the background wind, which facilitates the formation of a local critical layer. This result suggests that negative momentum forcing by equatorial waves preconditioned the extratropical Rossby wave breaking, which motivates the current study to investigate the role of each equatorial wave mode in the QBO disruption from early to later stages.

Coy et al. (2017) showed that about half of the negative momentum forcing required for the QBO disruption in February 2016 can be explained by the horizontal component of Eliassen-Palm flux (EPF) divergence (EPD), which is largely attributed to the Rossby waves that propagate from the extratropics. They mentioned that further analyses of the vertical component of the EPD are necessary given that the vertical EPF in the tropical region significantly increased during the disruption. Barton and McCormack (2017) also recognized the non-negligible contribution of the vertical
EPD, but no systematic analysis of the equatorial wave forcing has been undertaken since then.

In the present study, we examine the contributions of equatorial planetary waves, including equatorial Kelvin, Rossby, MRG, and inertia-gravity (IG) waves, and small-scale convective gravity waves (CGWs) to the 2015/16 QBO disruption by employing the separation method of equatorial wave modes of Kim and Chun (2015a) and the offline CGW parameterization by Kang et al. (2017) using the Modern-Era Retrospective Analysis for Research and Applications version 2 (MERRA-2) reanalysis data (Gelaro et al., 2017) on native model levels (GMAO, 2015). This is the first study to classify equatorial waves in detail and investigate each wave's role in the QBO disruption. Note that if the EPD is calculated without separating each wave mode, the importance of the westward-propagating waves might be obscured by the eastward-propagating waves, given that Kelvin wave activity was enhanced during the 2015/16 QBO disruption (Kumar et al., 2018; Li et al., 2020). The second new aspect of this study is to investigate the role of smallscale CGWs. Generally, small-scale CGWs have been recognized as an important driver of the easterly QBO (Kawatani et al., 2010; Evan et al., 2012; Ern et al., 2014; Kim and Chun, 2015a), but this has not been examined comprehensively in terms of the QBO disruption, except by Coy et al. (2017), who analyzed the role of the parameterized gravity wave drag (GWD) provided by MERRA-2, and by Watanabe et al. (2018), who simulated the QBO disruption with the JAGUAR model by resolving IG waves of horizontal wavelength longer than $\sim 200 \mathrm{~km}$. However, the parameterized GWD data provided by MERRA-2 are the combination of orographic and non-orographic GWDs, and the nonorographic GW parameterization assumes a latitudinally dependent GW source momentum flux without considering GW sources explicitly; thus, understanding the linkage between the convective source and the wave forcing was somewhat difficult. In particular, the QBO disruption took place during a strong El Niño phase, implying that CGW activity could be much stronger than the climatology. To overcome the simplicity of the non-orographic GW parametrization in MERRA-2 and the inevitable restriction on the horizontal resolution, in this study, we provide a realistic estimate of small-scale wave drag due to CGWs $\left(\lambda_{\mathrm{h}}<100\right.$ $200 \mathrm{~km}$, where $\lambda_{\mathrm{h}}$ is the horizontal wavelength) by using an offline, convectively coupled GW parameterization (Kang et al., 2017). The magnitude of the CGW momentum flux is constrained by observational data from super-pressure balloons in the tropical region (Jewtoukoff et al., 2013), which is the only tropical in situ observation covering small-scale GWs $\left(\lambda_{\mathrm{h}}<100 \mathrm{~km}\right)$.

In this study, we first examine the extent to which each equatorial wave contributes to the momentum budget during the QBO disruption. After determining how much wave forcing was anomalous compared to the climatology, we investigate the possible cause of the anomalous wave forc- 
ing during the QBO disruption. Section 2 of the paper describes the data and methods used in this study. In Sect. 3, general characteristics of zonal wind and equatorial waves during the QBO disruption are presented (Sect. 3.1), including quantitative estimates of momentum forcing by equatorial waves (Sect. 3.2). The detailed wave structures and their sources are discussed for Rossby waves and MRG waves (Sect. 3.3), inertia-gravity waves (Sect. 3.4), and small-scale CGWs (Sect. 3.5). Section 4 provides a summary of our findings, followed by concluding remarks.

\section{Data and methods}

\subsection{Data}

In this study, we use output from MERRA-2 for 37 years (from 1980 to 2016 ) provided on a $0.625^{\circ}$ longitude by $0.5^{\circ}$ latitude regular grid at $3 \mathrm{~h}$ intervals. We employ native model-level data for accuracy in estimating both resolved and parameterized wave forcing, especially for the equatorial waves having relatively short vertical wavelengths (e.g., MRG waves; Richter et al., 2014). The model-top pressure is $0.01 \mathrm{hPa}$ with 72 layers in total including 14 layers from 100 to $10 \mathrm{hPa}$. We utilize zonal wind, meridional wind, temperature, geopotential height, air temperature tendency due to moist processes (DTDTMST), large-scale rainfall, and convective rainfall. In addition to MERRA-2, output from the European Centre for Medium-Range Weather Forecasts (ECMWF) interim reanalysis (ERA-I; Dee et al., 2011) with a horizontal resolution of $0.75^{\circ}$ at $6 \mathrm{~h}$ intervals from 2015 to 2016 is used to examine the sensitivity of resolved wave forcing on the reanalysis datasets. The 3-hourly precipitation data from Tropical Rainfall Measuring Mission (TRMM) 3B42 version 7 (Huffman et al., 2014) for 19 years (1998-2016) with a horizontal resolution of $0.25^{\circ}$ are also used to confirm the precipitation variability in MERRA-2. For validating convective heating rate data estimated from MERRA2 (Sect. 2.4), which are input data for CGW parameterization, gridded convective stratiform heating (GCSH) estimated from Global Precipitation Measurement (GPM) observations (GPM Science Team, 2017; Lang and Tao, 2018) is used.

Here, we define a westerly QBO (WQBO) phase when the zonal wind anomaly from the monthly climatology divided by its SD exceeds +0.5 both at 30 and $50 \mathrm{hPa}$ for at least 4 months during the 6 months from October to March, the month when the QBO disruption develops. It should be noted that there are WQBO phases in other seasons as well, but we focus on the $\mathrm{NH}$ winter to compare with the 2015/16 QBO disruption. Based on this definition, 10 winters among 37 years are selected: 1980/81, 1982/83, 1985/86, 1987/88, 1990/91, 1999/2000, 2006/07, 2008/09, 2010/11, and 2013/14. The average of those 10 winters will be referred to as the climatology hereafter.

\subsection{Transformed Eulerian mean (TEM) momentum equation}

We use the transformed Eulerian mean (TEM) zonal momentum equation in log-pressure coordinates (Andrews et al., 1987) to examine the zonal wind acceleration, resolved wave forcing, and the vertical advection:

$$
\begin{aligned}
\frac{\partial \bar{u}}{\partial t} & =\left(f-\frac{1}{a \cos \phi} \frac{\partial}{\partial \phi}(\bar{u} \cos \phi)\right) \bar{v}^{*} \\
& -\bar{w}^{*} \frac{\partial \bar{u}}{\partial z}+\frac{1}{\rho_{0} a \cos \phi} \nabla \cdot F+\bar{X} .
\end{aligned}
$$

Here, $a, u$, and $\rho_{0}$ are the radius of the Earth, zonal wind, and air density, respectively. The overbar and prime indicate the zonal average and the perturbation from it, respectively. The EPF, expressed as $F \equiv\left(0, F^{\phi}, F^{z}\right)$, is composed of meridional $\left[F^{\phi}=\rho_{0} a \cos \phi\left(-\overline{u^{\prime} v^{\prime}}+\bar{u}_{z} \overline{v^{\prime} \theta^{\prime}} / \bar{\theta}_{z}\right)\right]$ and vertical $\left[F^{z}=\rho_{0} a \cos \phi\left(\hat{f} \overline{v^{\prime} \theta^{\prime}} / \bar{\theta}_{z}-\overline{u^{\prime} w^{\prime}}\right)\right]$ components, and its divergence (EPD) is calculated as follows:

$$
\begin{aligned}
\frac{1}{\rho_{0} a \cos \phi} \nabla \cdot F & =\frac{1}{\rho_{0} a \cos \phi} \\
\cdot & {\left[\frac{1}{a \cos \phi} \frac{\partial}{\partial \phi}\left(F^{\phi} \cos \phi\right)+\frac{\partial F^{z}}{\partial z}\right] . }
\end{aligned}
$$

In $F^{z}, \hat{f}$ is the modified Coriolis parameter defined by $\hat{f}=f-1 /(a \cos \phi) \partial / \partial \phi(\bar{u} \cos \phi)$, where $f$ is the Coriolis parameter, and $\bar{v}^{*}$ and $\bar{w}^{*}$ are the residual meridional and vertical velocities defined by $\bar{v}^{*}=\bar{v}-\rho_{0}^{-1}\left(\rho_{0} \overline{v^{\prime} \theta^{\prime}} / \bar{\theta}_{z}\right)_{z}$ and $\bar{w}^{*}=\bar{w}+(a \cos \phi)^{-1}\left(\cos \phi \overline{v^{\prime} \theta^{\prime}} / \bar{\theta}_{z}\right)_{\phi}$, respectively. $\bar{X}$ in Eq. (1) represents forcing by processes other than EPD, including parameterized GWD. Although MERRA-2 provides GWD, it is not coupled with the variation of the convection. Therefore, we calculated physically based and convectiondependent GW parameterization offline (Kang et al., 2017, 2018), which will be described in Sect. 2.4.

\subsection{Classification of the equatorial wave modes}

We separate equatorial waves into Kelvin, Rossby, MRG, and IG waves using the method proposed by Kim and Chun (2015a) with MERRA-2 reanalysis data. Here, we briefly describe the way to separate each wave component, and the details can be found in Sect. 4 of Kim and Chun (2015a). First, all the perturbation variables constituting the EPF are divided into symmetric and antisymmetric components with respect to the Equator for a $90 \mathrm{~d}$ segment after applying sine and cosine windows at the first and last $30 \mathrm{~d}$, respectively. Second, a two-dimensional Fourier transform is performed on the perturbation variables with respect to longitude and time to obtain their zonal wavenumber-frequency $(k-\omega)$ spectra at each latitude and height from $30^{\circ} \mathrm{N}$ to $30^{\circ} \mathrm{S}$ and 100 to $5 \mathrm{hPa}$. Kelvin waves are confined to the spectral range of $0<k \leq 20$ and $\omega<0.75 \mathrm{cpd}$ (cycles per day) in the symmetric spectrum in the latitude range where $\left|F^{z 1}\right|<\left|F^{z 2}\right|$. 
Here, $F^{z 1}$ and $F^{z 2}$ represent the first and second terms of the vertical component of $\mathrm{EPF}\left(F^{z}\right)$, respectively. MRG waves are confined to the range $|k| \leq 20$ and $0.1 \leq \omega \leq 0.5 \mathrm{cpd}$ in the antisymmetric spectrum within the latitude range where $F^{z 1} \cdot F^{z 2}<0$. Generally, the dominant zonal wavenumbers for MRG waves are $|k| \leq 10$. The spectral ranges that are not classified as Kelvin or MRG waves are defined as Rossby waves for the ranges $|k| \leq 20$ and $\omega \leq 0.4$ cpd and IG waves otherwise. Finally, EPF and EPD calculated at a given $k$ and $\omega$ are summed over the spectral range of each wave mode using Parseval's relation (Horinouchi et al., 2003) and multiplied by a scale factor of $3 / 2$ to conserve the original variance (Kim et al., 2019). Note that the westward waves (intrinsic frequency $<0$ ) propagate in the same direction as the EPF vectors, whereas the eastward waves (intrinsic frequency $>0$ ) propagate in the opposite direction of the EPF vectors (Andrews et al., 1983). Therefore, given the dominant upward propagation in the stratosphere, EPF vectors for the Rossby, MRG, and westward IG waves are directed upward, whereas those for the Kelvin waves and eastward IG waves are directed downward.

In the troposphere, the abovementioned method is not suitable for classifying each wave mode (Kim and Chun, 2015a) because the source of the stratospheric equatorial waves, such as convection, contaminates the $F^{z 1}$ and $F^{z 2}$. Therefore, we instead apply very simple criteria to separate the wave spectrum below $100 \mathrm{hPa}$ as follows: in the frequency range of $\omega \leq 0.4 \mathrm{cpd}$, the perturbation variables in the ranges of $0<k \leq 20$ and $-20 \leq k<0$ are defined as low-frequency eastward $\left(L_{\mathrm{e}}\right)$ and westward $\left(L_{\mathrm{w}}\right)$ waves, respectively, which approximately represent Kelvin and Rossby waves. The variables in the spectral ranges of (i) $k>20$ or (ii) $0<k \leq 20$ with $\omega>0.4 \mathrm{cpd}$ and those of (i) $k<-20$ or (ii) $-20 \leq k<$ 0 with $\omega>0.4 \mathrm{cpd}$ are defined as high-frequency eastward $\left(H_{\mathrm{e}}\right)$ and westward $\left(H_{\mathrm{w}}\right)$ waves, respectively, which approximately represent eastward and westward IG waves. It is noteworthy that the source level of $H_{\mathrm{e}}\left(H_{\mathrm{w}}\right)$ waves is likely located at $150 \mathrm{hPa}$ and below ( $140 \mathrm{hPa}$ and above) based on the changes in the direction of EPF vectors and the sign of EPD (Fig. S1). Therefore, in this study, we simply assume the source level of $H_{\mathrm{e}}+H_{\mathrm{w}}$ waves as $140 \mathrm{hPa}$. The separation method in the troposphere enables us to identify the source location of the anomalously strong waves observed in the stratosphere.

\subsection{Offline CGW parameterization}

We apply the offline CGW parameterization using MERRA2 data focusing on small-scale waves $\left(\lambda_{\mathrm{h}}<100 \mathrm{~km}\right.$ and $\lambda_{z}<40 \mathrm{~km}$, where $\lambda_{z}$ is the vertical wavelength), which is similar to the work of Kang et al. $(2017,2018)$ using NCEP Climate Forecast System Reanalysis (CFSR; Saha et al., 2010) data. The offline CGW parameterization calculates GW momentum flux induced by convective heating rate at the source level (cloud top) as a function of phase velocity; the GW momentum flux and drag from the cloud top to the stratosphere are calculated based on columnar wave propagation by using Lindzen's saturation theory (Lindzen, 1981). The parameterization requires convective heating rate and convective cloud-top and cloud-bottom heights in addition to standard variables such as wind, temperature, and geopotential height as input data. MERRA-2 provides only cloud-top height without convective heating rate, so we tried to extract convection-induced heating rate from the MERRA-2 output field DTDTMST; this field contains all processes that contribute to latent heating by moist convection, not exclusively by cumulus convection (Bosilovich et al., 2016). To reconcile this limitation, we select cases that satisfy several criteria to represent clouds that can generate convective GWs. First, we only considered DTDTMST profiles in which column maximum height is higher than $850 \mathrm{hPa}$. Second, we estimated the convective cloud-top and cloud-bottom heights as the locations where DTDTMST falls to $20 \%$ and $5 \%$, respectively, from its maximum. Here, the convective cloud top should not exceed the cloud-top height provided by MERRA-2. Although $20 \%$ seems large, we decided to use the value considering the large tail in the upper part of the DTDTMST profile (Fig. S2). Note that the cloud-top height is provided by MERRA-2, but we chose instead to estimate it from the DTDTMST profile because the cloud-top heights in MERRA2 are sometimes too high due to stratiform clouds, such as anvil clouds, which do not represent the top height of the convection properly. Third, when (i) the convective cloudtop height is at altitudes lower than $700 \mathrm{hPa}$, (ii) the convective cloud-bottom height is higher than $7 \mathrm{~km}$, or (iii) the convective cloud depth is shallower than $1 \mathrm{~km}$, the profiles are eliminated. The DTDTMST profiles selected using the aforementioned procedure will be referred to as convective heating profiles hereafter; they are generally similar to the convection-induced heating profiles estimated from GPM observations (Fig. S2). Note that the magnitude of the CGW momentum flux is constrained by the observed GW momentum flux from super-pressure balloons in the tropical region (Jewtoukoff et al., 2013). Because spatiotemporal variations in convective activity and background flows are considered in the parameterization, it is valuable to investigate the variations in the magnitude and the spectral shape of the CGW momentum flux during the QBO disruption.

\subsection{Baroclinic instability}

Baroclinic instability, a possible source of MRG waves, can be evaluated using the meridional gradient of the potential vorticity (Andrews et al., 1987):

$\bar{q}_{\phi}=2 \Omega \cos \phi-\left[\frac{(\bar{u} \cos \phi)_{\phi}}{a \cos \phi}\right]_{\phi}-\frac{a}{\rho_{0}}\left(\frac{\rho_{0} f^{2}}{N^{2}} \bar{u}_{z}\right)_{z}$,

where $\Omega$ is the Earth's rotation and $N$ is the buoyancy frequency. Negative regions of $\bar{q}_{\phi}$ suggest the possibility of instability because positive and negative $\bar{q}_{\phi}$ values in a 
(a)
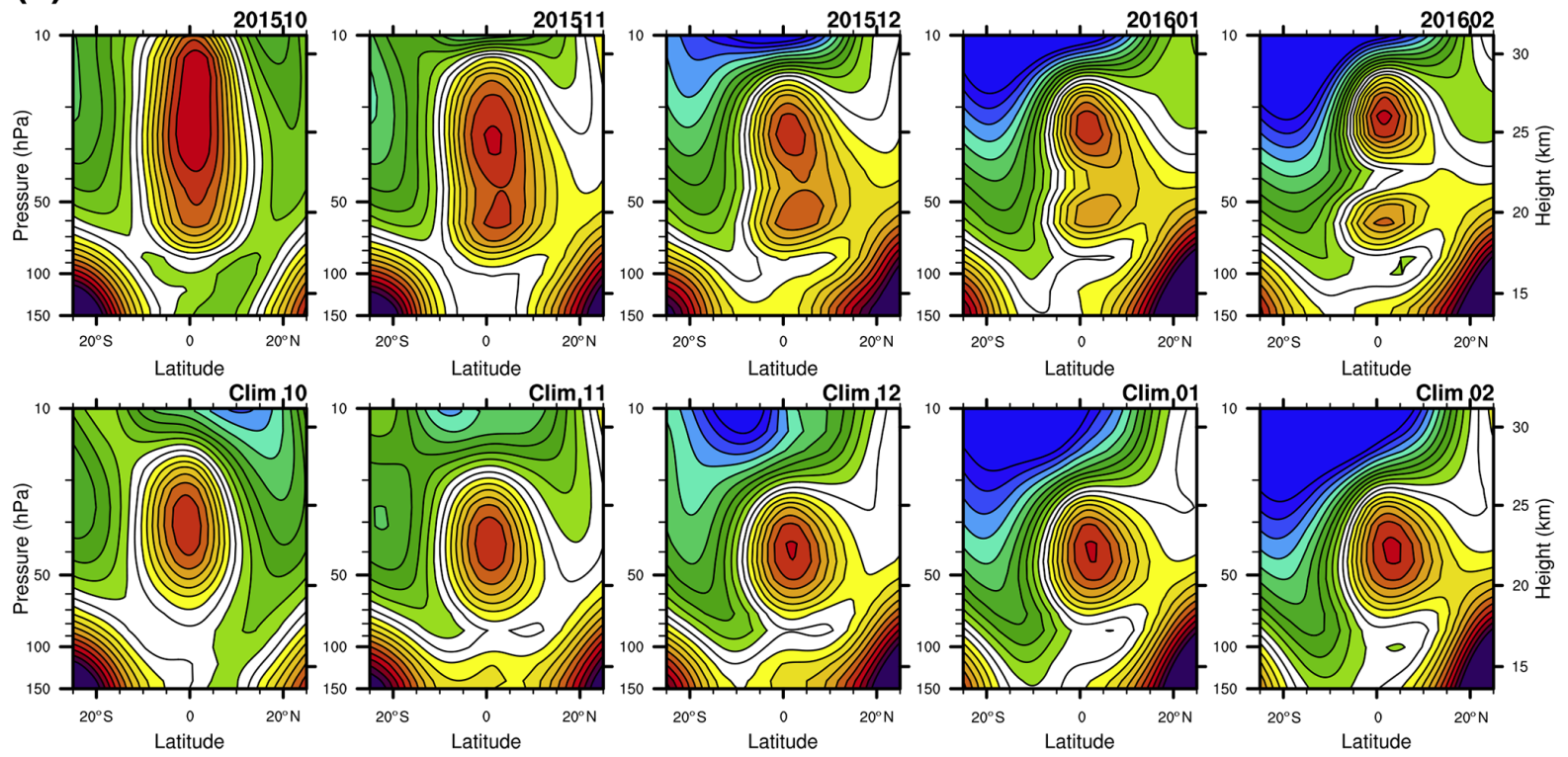

(b)
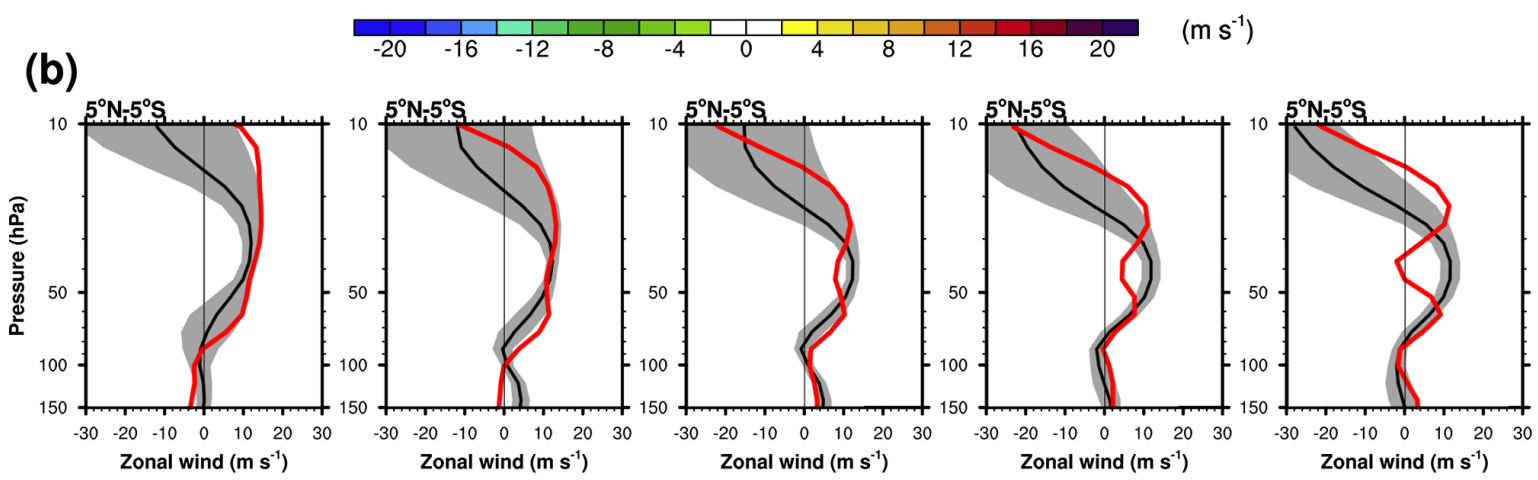

Figure 1. (a) Latitude-height cross sections of the zonal-mean zonal wind from October 2015 to February 2016 and (bottom) their climatology in each month from October to February. (b) Zonal-mean zonal wind averaged between $5^{\circ} \mathrm{N}$ and $5^{\circ} \mathrm{S}$ from October 2015 to February 2016. Red lines represent the QBO disruption and black lines represent the climatology with \pm 1 SD (gray shading). Note that the climatology is for WQBO years.

neighboring region are a necessary condition for instability (Gill, 1982). This instability may be barotropic or baroclinic. In this study negative $\bar{q}_{\phi}$ is considered an indication of barotropic instability because the baroclinic term (third term) is negligible (not shown).

\section{Results}

\subsection{General characteristics of zonal wind and equatorial waves}

Figure 1 shows zonal-mean zonal wind in a latitude-height cross section from October 2015 to February 2016, monthly climatology from October to February (Fig. 1a), and the zonal-mean zonal wind profile averaged over $5^{\circ} \mathrm{N}-5^{\circ} \mathrm{S}$ during the disruption compared with its monthly climatology (Fig. 1b). Again, the climatology here refers to that of the WQBO phases defined in Sect. 2.1. In October 2015, the WQBO is very deep compared to the climatology. The WQBO starts to split into two maxima as early as November 2015 (Fig. 1a), and the westerly wind becomes anomalously weak at $40-50 \mathrm{hPa}$ by more than $1 \sigma$, where $\sigma$ is the standard deviation (SD) of the zonal-mean zonal wind in December 2015 (Fig. 1b). In January 2016, the zonal wind at $40 \mathrm{hPa}$ continuously decelerates and then changes to easterly in February. From January 2016, the zonal wind at the altitude above $30 \mathrm{hPa}$ exhibits a strong westerly wind greater than the climatology by more than $1 \sigma$ (Fig. 1b), indicating that the WQBO is anomalously deep. In the upper troposphere (100-150 hPa), easterly anomalies are shown in November 2015, but from January 2016, westerly anomalies appear.

Figure 2 shows latitude-height cross sections of the EPF and EPD for each type of wave in February 2016. Note that 

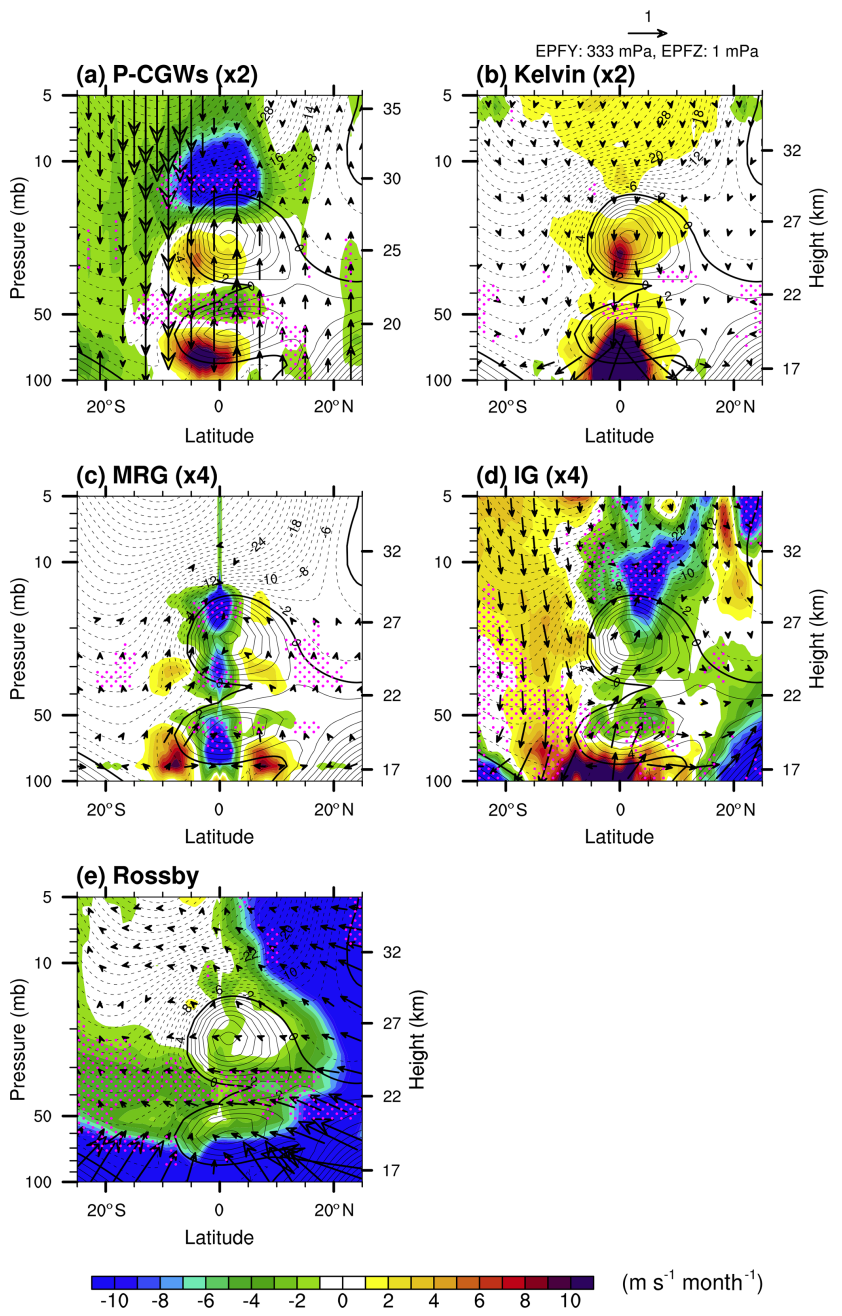

Figure 2. Latitude-height cross sections of the EPF (vectors) and EPD (shading) for the (a) parameterized CGWs (P-CGWs, multiplied by 2) and resolved equatorial waves, including (b) Kelvin (multiplied by 2), (c) MRG (multiplied by 4), (d) inertia-gravity (IG, multiplied by 4), and (e) Rossby waves, superimposed on the zonal-mean zonal wind (contour) in February 2016. Positive (negative) zonal winds are plotted with solid (dashed) lines with a contour interval of $2 \mathrm{~m} \mathrm{~s}^{-1}$, and thick contour lines denote a zero zonal wind speed. The magenta stippled pattern represents a region where the EPD is algebraically smaller (more negative) than the climatology by more than its SD. The arrow in the upper right corner denotes the reference vector.

the parameterized CGW momentum flux $\left(\rho_{0} \overline{u^{\prime} w^{\prime}}\right)$ is multiplied by $(-\cos \phi)$ to display the vertical EPF vectors of CGWs, and each of the wave forcings and vectors in Fig. 2 is scaled differently in order to mainly focus on their morphology. The EPD more negative than climatology by more than $1 \sigma$ is stippled, which represents anomalously strong negative wave forcing. The parameterized CGWs (P-CGWs in Fig. 2a) generally exert a positive (negative) drag on the zonal wind in regions of positive (negative) wind shear, respectively, with the strongest negative forcing at $7-20 \mathrm{hPa}$ between $5^{\circ} \mathrm{N}$ and $10^{\circ} \mathrm{S}$. The negative CGW forcing at 40 $50 \mathrm{hPa}$ between $10^{\circ} \mathrm{N}$ and $10^{\circ} \mathrm{S}$ is anomalously strong. At $20^{\circ} \mathrm{N}-5^{\circ} \mathrm{S}$, westward-propagating P-CGWs are dominant, which can be inferred from the direction of vertical EPF vectors.

Kelvin waves (Fig. 2b) exert positive wave forcing in the positive shear zone, strengthening the bottom side of the westerly jet. Therefore, Kelvin waves may help to maintain two westerly jets (5-30 and 50-80 hPa) with a developing easterly jet in between, as in Fig. 3c of Lin et al. (2019). This result is also consistent with the findings of $\mathrm{Li}$ et al. (2020), who showed the contribution of strong Kelvin wave activity related to an El Niño event to the long-lasting westerly jet near $20 \mathrm{hPa}$. MRG waves (Fig. 2c) show anomalously strong negative forcing at 50-80, 30-40, and $15-20 \mathrm{hPa}$ concentrated at the Equator. They seem to be generated in the altitude range 60-90 and 30-40 hPa in which the EPD has positive values at $5-10^{\circ} \mathrm{N}-\mathrm{S}$, which is also revealed in Fig. $3 \mathrm{~b}$ of Lin et al. (2019). As will be shown later, the effect of the MRG waves is to flatten the meridional profile of the westerly jet, possibly making the jet more sensitive to erosion by other waves, such as Rossby waves.

IG waves (Fig. 2d), which have not been reported before, exhibit a negative forcing near the Equator $\left(10^{\circ} \mathrm{N}-10^{\circ} \mathrm{S}\right)$ from 70 to $5 \mathrm{hPa}$ with a maximum forcing at $8-20 \mathrm{hPa}$, while the anomalously strong negative IG wave forcing is mainly located at 50-70 and 8-20 hPa. The negative Rossby wave forcing (Fig. 2e) is anomalously stronger than the climatology at $30-50 \mathrm{hPa}$ between $20^{\circ} \mathrm{N}$ and $25^{\circ} \mathrm{S}$, which is attributed to waves that propagate from the $\mathrm{NH}$ extratropics as in previous studies. The same information for the whole QBO disruption period from October 2015 to March 2016 is shown in Fig. S3.

Figure 3 shows time-height cross sections of the zonal wind, zonal wind tendency, vertical advection (the second term on the right-hand side of Eq. 1), required wave forcing, and forcing due to each type of wave averaged over $5^{\circ} \mathrm{N}-$ $5^{\circ} \mathrm{S}$ from July 2015 to June 2016 , as well as their monthly climatology from July to June. The required wave forcing term (REQ) is calculated as a residual by subtracting both the meridional and vertical advection terms from the zonal wind tendency in the TEM equation. In Fig. 3a, both the zonal-mean zonal wind during the disruption and the climatology propagate downward with time, but the WQBO is much deeper during the disruption than in the climatology. This feature is clearly seen in the difference plot of the zonal-mean zonal wind (Fig. 3b), showing a strong westerly anomaly in the upper stratosphere. The westerly wind decelerates at $40 \mathrm{hPa}$ from October 2015 , changes to easterly in February 2016, and starts to propagate downward as an easterly QBO phase afterward. The deceleration of the westerly wind at $40 \mathrm{hPa}$ is also revealed in the zonal wind tendency (Fig. 3c), as the negative wind tendency at $40 \mathrm{hPa}$ becomes anomalously strong in October 2015. 
2015/16

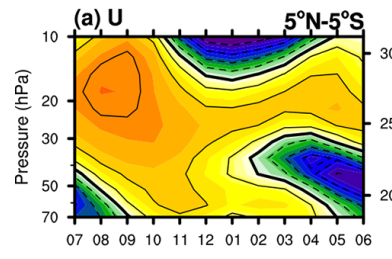

(c) $\partial U / \partial t$

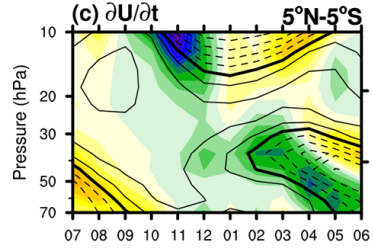

(e) REQ

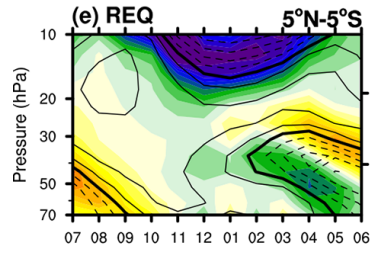

(g) Kelvin (x4)

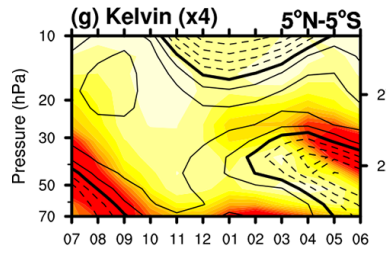

(i) IG (x4)

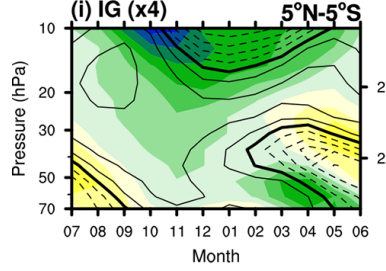

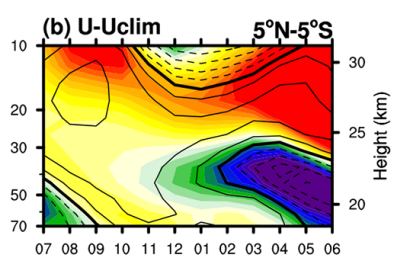
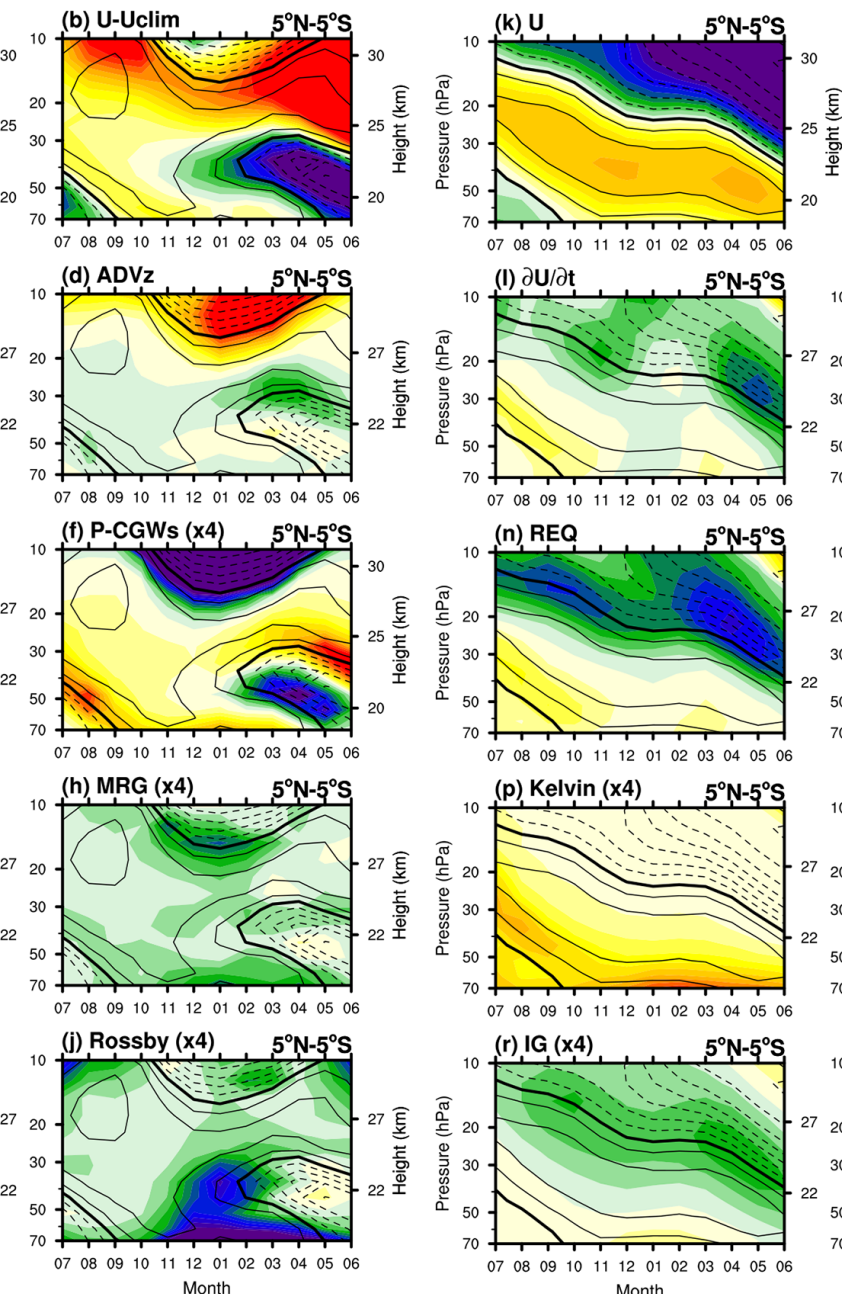

$\begin{array}{llllllll}11 & 12 & 01 & 02 & 03 & 04 & 05 & 06\end{array}$
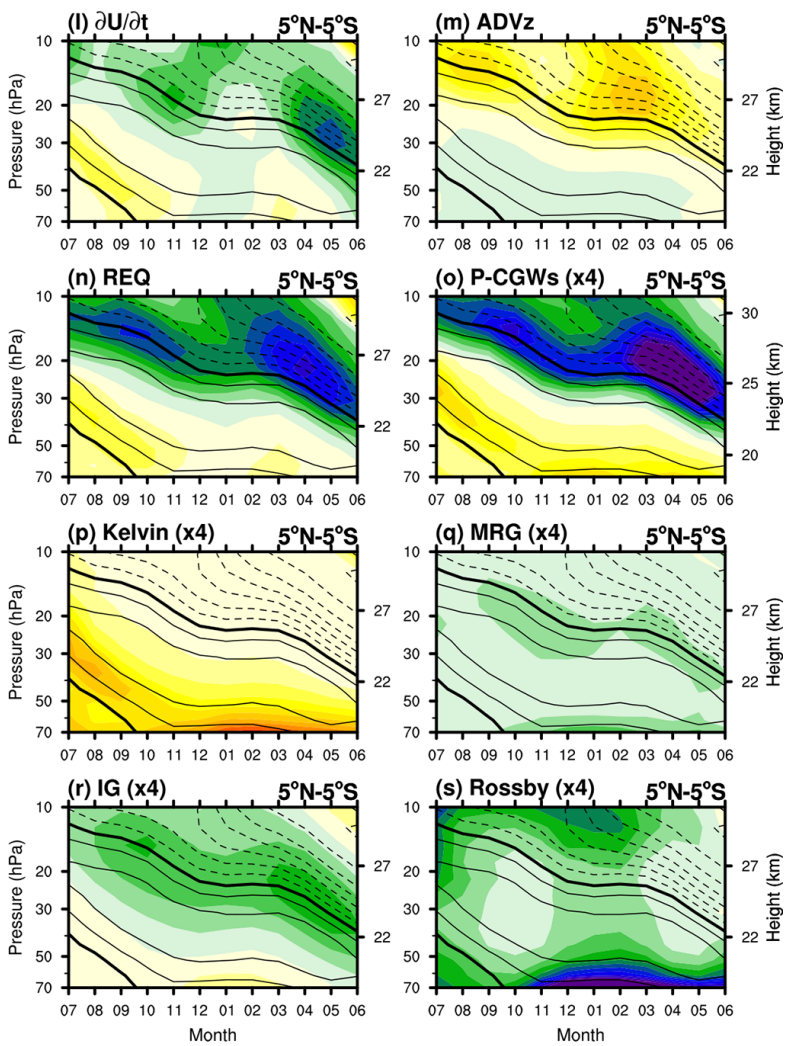

(a)-(b), (k) $\left[\mathrm{m} \mathrm{s}^{-1}\right]$

(c)-(j), (l)-(s) $\left[\mathrm{m} \mathrm{s}^{-1}\right.$ month $\left.^{-1}\right]$

Figure 3. Time-height cross sections of the (a) zonal-mean zonal wind $(U)$, (b) zonal wind anomaly from the climatology (U-Uclim), (c) zonal wind tendency $(\partial U / \partial t)$, (d) vertical advection (ADVz), (e) required wave forcing (REQ) in the TEM equation, and EPD for the (f) P-CGWs, (g) Kelvin, (h) MRG, (i) IG, and (j) Rossby waves (left) from July 2015 to June 2016 and (k-s) their climatology from July to June, overlaid with the zonal-mean zonal wind (black contour lines). Positive (negative) zonal winds are plotted with solid (dashed) lines with a contour interval of $5 \mathrm{~m} \mathrm{~s}^{-1}$, and thick contour lines denote a zero zonal wind speed.

To investigate whether vertical advection contributes to the anomalous zonal wind tendency near $40 \mathrm{hPa}$, the vertical advection term (ADVz) in the TEM equation is shown in Fig. 3d. Climatologically, the sign of the equatorial wave forcing is the same as that of the vertical wind shear (Fig. $3 \mathrm{~m}$ ). Therefore, positive $\bar{w}^{*}$ makes the sign of ADVz opposite to that of the vertical wind shear (Eq. 1), acting to oppose the zonal wind tendency (Dunkerton, 1991). From November to December 2015 at $40 \mathrm{hPa}$, however, ADVz has the same negative sign as the zonal wind tendency because both $\bar{w}^{*}$ and vertical wind shear are positive (not shown), while the wave forcing is negative regardless of the positive wind shear. Therefore, ADVz acts to accelerate the easterly development by $17 \%$ and $2 \%$ of the zonal wind tendency, respectively, with values of -0.3 and $-0.1 \mathrm{~m} \mathrm{~s}^{-1}$ per month in November and December 2015. This implies that ADVz also contributes to the QBO disruption in the early stages.

The climatology of REQ (Fig. 3n) has negative (positive) values in the regions of negative (positive) vertical wind shear, but a sudden increase in negative REQ emerges at $40 \mathrm{hPa}$ in October 2015 (Fig. 3e) without negative vertical wind shear. The estimated wave forcing by P-CGWs (Fig. 3f) resembles REQ, especially at the upper stratosphere where strong negative wind shear exists and in the altitude range between 40 and $70 \mathrm{hPa}$ after the intrusion of the easterly wind. This indicates that the P-CGWs largely contribute to 
the QBO disruption after the negative wind shear appears near $40 \mathrm{hPa}$ (i.e., after February 2016). Kelvin wave forcing during the disruption (Fig. $3 \mathrm{~g}$ ) is much greater than the climatology (Fig. 3p) near the altitude of 30 and $60 \mathrm{hPa}$ due to the positive wind shear. The wave forcing could be stronger because of the strong vertical wave flux propagating from the troposphere, which is identified by the enhanced vertical EPF for the Kelvin waves at $70 \mathrm{hPa}$ (Fig. S4). The positive forcing near 30 and $60 \mathrm{hPa}$ from January to March 2016 accelerates the upper and lower jets, respectively, and thereby the upper and lower parts of the QBO jet are not totally dissipated, maintaining the separated jet during the disruption (Fig. 2). Acceleration in the upper and lower parts of the separated QBO jet is also shown by the momentum forcing by $\mathrm{P}$ CGWs (Fig. 3f). The contribution of CGWs to the enhanced jet in the current study may explain why the westerly winds simulated by Watanabe et al. (2018) are relatively weak compared to those in MERRA-2 near 20 and $70 \mathrm{hPa}$, without a non-orographic $\mathrm{GW}$ parameterization.

MRG wave forcing is generally stronger during the disruption (Fig. 3h) than in the climatology (Fig. 3q). In addition, there is a sudden increase in the negative MRG forcing at $40 \mathrm{hPa}$ from October to November 2015, which is similar to the pattern seen in REQ at this time and location. This suggests that the MRG waves influence the early stage of the QBO disruption by slowing down the QBO jet. IG waves (Fig. 3i) exert a strong negative forcing in November 2015, which might be related to the enhancement of negative REQ near $40 \mathrm{hPa}$ along with the MRG wave forcing. Rossby wave forcing (Fig. 3j) near $40 \mathrm{hPa}$ is consistently stronger than the climatology from November 2015 to March 2016, which is considered to be a major cause of the QBO disruption.

To summarize, in October 2015, the negative forcing by MRG waves is anomalously strong compared to the climatology at $40 \mathrm{hPa}$ between $5^{\circ} \mathrm{N}$ and $5^{\circ} \mathrm{S}$, and it becomes stronger in November 2015 together with IG waves when the Rossby waves start to break at the southern hemispheric (SH) part of the QBO (see Fig. 5). Therefore, MRG and IG wave forcing may precondition the zonal mean flow near the QBO jet core to be easily disrupted by the Rossby waves. This result is similar to the suggestion by Lin et al. (2019) that MRG waves precondition the zonal mean flow before Rossby wave breaking. From December 2015 to February 2016, the Rossby wave forcing is dominant among the equatorial waves, while the negative CGW forcing significantly contributes to the disruption in February 2016 when negative vertical wind shear appears near $40 \mathrm{hPa}$. Figure S5 shows the same as Fig. 3 but using ERA-I data. We found that the time evolution of each wave forcing in ERA-I is similar to that in MERRA-2, although the magnitudes of the REQ and wave forcing (vertical advection) in ERA-I are generally stronger (weaker) than in MERRA-2 (Fig. S5). This is possibly due to the large spread in both $\bar{w}^{*}$ and vertical wind shear between the reanalyses (see Fig. 5 of Kim and Chun, 2015b).

\subsection{Quantitative contributions of the equatorial waves}

Figure 4 shows the time series of zonal wind, zonal wind tendency, and wave forcing by each type of wave from July 2015 to June 2016 at $40 \mathrm{hPa}$. The monthly averaged momentum forcing by each type of wave and its contribution to the total negative wave forcing (percentage) are given in Table 1. The zonal wind (Fig. 4a, solid line) changes to easterly in February 2016, whereas the zonal wind tendency (Fig. 4a, dotted line) changes to a negative value in October 2015, as shown in Fig. 3. The negative zonal wind tendency in October 2015 is induced by both MRG $\left(-0.43 \mathrm{~m} \mathrm{~s}^{-1}\right.$ per month) and IG waves $\left(-0.46 \mathrm{~m} \mathrm{~s}^{-1}\right.$ per month), with contributions of $39 \%$ and $41 \%$, respectively, while Rossby wave forcing is $-0.22 \mathrm{~m} \mathrm{~s}^{-1}$ per month, with a relatively small contribution of $20 \%$ (Fig. 4b). In November 2015, negative wave forcing by Rossby, MRG, and IG waves increases with contributions of $45 \%, 27 \%$, and $28 \%$, respectively, which are $2.4,2.5$, and 1.6 times stronger than the climatology. Afterward, Rossby waves mainly provide negative forcing, which induces easterly accelerations in December 2015 and January 2016 , with contributions of $70 \%$ and $91 \%$ to the total negative forcing, respectively. They are 3.2 and 4.3 times larger than the climatology, respectively. In February 2016, Rossby waves, parameterized CGWs, MRG waves, and IG waves at $40 \mathrm{hPa}$ contribute to the total negative wave forcing by $61 \%$, $20 \%, 12 \%$, and $7 \%$, respectively. The CGWs dominate the negative forcing with a percentage of $60 \%$ in March 2016. When the average is taken over $5-10^{\circ} \mathrm{S}$, however, Rossby waves dominate from October 2015 (Fig. S7). This implies that the Rossby wave forcing was strong enough to decelerate the edge of the QBO jet $\left(5-10^{\circ} \mathrm{S}\right)$, while it presumably extends to the jet core $\left(0-5^{\circ} \mathrm{S}\right.$; Fig. 5) due to the weakening of the QBO jet by the MRG (Fig. 7) and IG (Fig. 11) wave forcing near the Equator. When we compare Fig. 4b and d, a similarity between the time evolution of the meridional (vertical) wind shear and that of the Rossby wave (CGW) forcing is shown. This is because the magnitude of the meridional (vertical) wind shear largely determines or is determined by that of the Rossby wave forcing (GWD). A similar time evolution of the equatorial wave forcing is shown in ERA-I (Fig. S6), but the IG wave forcing is somewhat smaller than that in MERRA-2, possibly due to a coarser horizontal resolution.

Coy et al. (2017) showed that the positive peak of GWD in July 2015 is $4.5 \mathrm{~m} \mathrm{~s}^{-1}$ per month and the negative GWD in February 2016 is $-0.5 \mathrm{~m} \mathrm{~s}^{-1}$ per month (see their Fig. 2). In the current study, the positive peak of CGW drag (CGWD) in July 2015 is $3.75 \mathrm{~m} \mathrm{~s}^{-1}$ per month and the negative CGWD in February 2016 is $-1.0 \mathrm{~m} \mathrm{~s}^{-1}$ per month. There are two potential reasons for this discrepancy. First, the GWD reported by Coy et al. (2017) is provided by MERRA-2, which is based on a non-orographic GWD parameterization that does not explicitly consider GW sources. The CGWD in the current study is obtained from the physically based CGWD parameterization, which takes into account the GW variability 
$5^{\circ} \mathrm{N}-5^{\circ} \mathrm{S}, 40 \mathrm{hPa}(2015 / 16)$
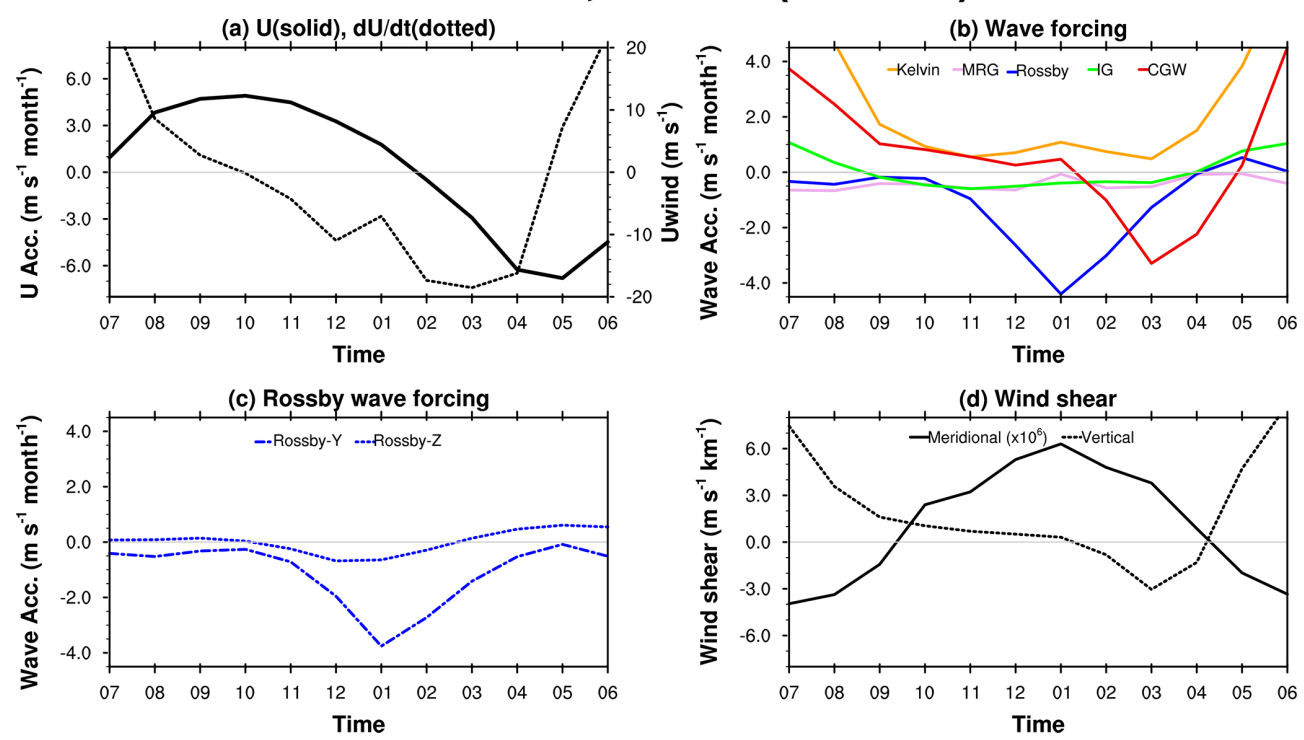

Figure 4. Time series of the (a) zonal-mean zonal wind (solid) and zonal wind tendency (dotted); (b) wave forcing by Kelvin waves (orange), MRG waves (pink), Rossby waves (blue), IG waves (light green), and CGWs (red); (c) meridional (dot-dashed) and vertical components (dotted) of the Rossby wave forcing; and (d) meridional wind shear across the Equator (solid) and vertical wind shear averaged over $5^{\circ} \mathrm{N}-$ $5^{\circ} \mathrm{S}$ (dotted) at $40 \mathrm{hPa}$ from July 2015 to June 2016.

Table 1. Momentum forcing at $40 \mathrm{hPa}$ by each wave $\left(\mathrm{m} \mathrm{s}^{-1}\right.$ per month) and its percentage contribution to the total negative wave forcing (parentheses) averaged over $5^{\circ} \mathrm{N}-5^{\circ} \mathrm{S}$ from October 2015 to March 2016 and for the climatology. The percentage is calculated when a wave forcing is negative during the $\mathrm{QBO}$ disruption.

\begin{tabular}{lrrrrrr}
\hline 2015/16 & Oct 2015 & Nov 2015 & Dec 2015 & Jan 2016 & Feb 2016 & Mar 2016 \\
\hline MRG & $-0.4(39 \%)$ & $-0.6(27 \%)$ & $-0.6(17 \%)$ & $-0.1(1 \%)$ & $-0.6(12 \%)$ & $-0.5(10 \%)$ \\
IG & $-0.5(41 \%)$ & $-0.6(28 \%)$ & $-0.5(13 \%)$ & $-0.4(8 \%)$ & $-0.3(7 \%)$ & $-0.4(7 \%)$ \\
Rossby & $-0.2(20 \%)$ & $-0.9(45 \%)$ & $-2.6(70 \%)$ & $-4.4(91 \%)$ & $-3.0(61 \%)$ & $-1.3(23 \%)$ \\
CGW & 0.8 & 0.6 & 0.3 & 0.5 & $-1.0(20 \%)$ & $-3.3(60 \%)$ \\
Kelvin & 0.9 & 0.6 & 0.7 & 1.1 & 0.7 & 0.5 \\
\hline Rossby-Y & $-0.3(30 \%)$ & $-0.7(34 \%)$ & $-1.9(52 \%)$ & $-3.8(78 \%)$ & $-2.7(55 \%)$ & $-1.4(25 \%)$ \\
Rossby-Z & 0.03 & $-0.2(11 \%)$ & $-0.7(18 \%)$ & $-0.6(13 \%)$ & $-0.3(6 \%)$ & 0.1 \\
\hline Climatology & Oct & Nov & Dec & Jan & Feb & Mar \\
\hline MRG & -0.3 & -0.2 & -0.2 & -0.2 & -0.1 & -0.1 \\
IG & -0.2 & -0.4 & -0.4 & -0.4 & -0.3 & -0.4 \\
Rossby & -0.3 & -0.4 & -0.8 & -1.0 & -1.1 & -0.8 \\
CGW & 1.0 & 0.6 & 0.5 & 0.5 & 0.5 & 0.5 \\
Kelvin & 1.6 & 1.2 & 1.0 & 1.0 & 1.0 & 0.9 \\
\hline Rossby-Y & -0.2 & -0.3 & -0.6 & -0.8 & -0.9 & -0.6 \\
Rossby-Z & -0.1 & -0.1 & -0.2 & -0.2 & -0.2 & -0.2 \\
\hline
\end{tabular}

according to the convective activity. Second, there are some differences in analysis, such as the latitude range for averaging $\left(10^{\circ} \mathrm{N}-10^{\circ} \mathrm{S}\right.$ in Coy et al., 2017, but $5^{\circ} \mathrm{N}-5^{\circ} \mathrm{S}$ for the present study) and the vertical grids (pressure level in Coy et al., 2017, but model level for the present study). When we set the average latitude as $10^{\circ} \mathrm{N}-10^{\circ} \mathrm{S}$, the CGWD in Febru- ary 2016 is about $-0.7 \mathrm{~m} \mathrm{~s}^{-1}$ per month, which is still greater than the GWD reported by Coy et al. (2017). This implies that the negative momentum forcing by CGWs is stronger than that by GWs from a fixed source during the disruption.

Figure $4 \mathrm{c}$ shows the meridional and vertical components of the Rossby wave forcing at $40 \mathrm{hPa}$. The magnitude of 
the meridional component is larger than that of the vertical component and becomes dominant in December, January, and February when the negative wave forcing prevails. This demonstrates the importance of meridional propagation from the extratropics, as also reported from previous studies (e.g., Coy et al., 2017; Osprey et al., 2016). However, the vertical component is not negligible given that the maximum contribution of the vertical component to the total Rossby wave forcing reaches $26 \%$, which is $18 \%$ of the total negative wave forcing, in December 2015 (Table 1). The strong vertical EPD in the stratosphere $(40 \mathrm{hPa})$ does not necessarily indicate wave propagation from the equatorial region. Hence, the origin of the vertical Rossby wave forcing will be analyzed in the following subsection.

\subsection{Contributions of Rossby waves and MRG waves}

In this subsection, we focus on the Rossby and MRG waves as well as their sources. Figure 5 shows the evolution of the EPF and EPD for Rossby waves (left) and their meridional (middle) and vertical (right) components, separately, from November 2015 to February 2016. The vertical profiles of meridional EPF (EPF-y) at $10^{\circ} \mathrm{N}$ and $10^{\circ} \mathrm{S}$ are included, and the meridional distribution of the vertical EPF (EPF-z) at $70 \mathrm{hPa}$ is plotted at the bottom of each month in red lines. In the vertical profiles and meridional distribution plots, climatological monthly means are included as black lines with $\pm 1 \sigma$ values indicated in gray shading. Note that in the following figures, the EPF is divided by air density for better visualization. In November 2015 (Fig. 5a), the Rossby waves start to break at the southern flank of the QBO westerly jet near $50 \mathrm{hPa}$, which is anomalously strong compared to the climatology. They most likely propagate from the NH, given that EPF-y at $10^{\circ} \mathrm{N}$ is directed southward with a magnitude greater than the climatology by more than $1 \sigma$. The EPF-y at $10^{\circ} \mathrm{S}$ is directed northward at the altitude below $70 \mathrm{hPa}$, and it is slightly stronger than the climatology; however, this EPF hardly propagates into the QBO jet. In December 2015 (Fig. 5b), anomalously strong negative EPD near $40 \mathrm{hPa}$ in the $\mathrm{SH}$ extends northward to $10^{\circ} \mathrm{N}$, with the strong EPF-y at $10^{\circ} \mathrm{N}$ propagating toward the $\mathrm{SH}$. The negative EPD in the $\mathrm{SH}$ part of the $\mathrm{QBO}$ jet at $40 \mathrm{hPa}$ is mainly explained by its meridional component, which presumably originates from the EPF-y at $10^{\circ} \mathrm{N}$ between 70 and $30 \mathrm{hPa}$. On the other hand, the negative EPD in the NH part of the QBO jet at $40 \mathrm{hPa}$ is mainly explained by its vertical component considering the anomalously strong vertical EPD there. The strong vertical EPD seems to originate from the EPF-z at $70 \mathrm{hPa}$ between 0 and $15^{\circ} \mathrm{N}$. In January 2016 (Fig. 5c) when the Rossby wave forcing is the strongest, the overall feature is similar to December 2015 although with somewhat different aspects: (i) negative EPD at $40 \mathrm{hPa}$ exhibits a significant peak at $0-5^{\circ} \mathrm{S}$, (ii) EPF-y at $10^{\circ} \mathrm{N}$ has an additional peak at $40 \mathrm{hPa}$, and the (iii) EPF-z at $70 \mathrm{hPa}$ in the $\mathrm{SH}$ becomes much stronger than the climatology. In February 2016 (Fig. 5d), the anomalously strong negative EPD is more concentrated at $40 \mathrm{hPa}$ with a larger contribution from the meridional EPD at $0-25^{\circ} \mathrm{N}$, while the vertical EPF at $70 \mathrm{hPa}$ is less pronounced compared to January. To sum up, the Rossby wave forcing and the associated wave flux are anomalously strong from November 2015 to February 2016, and both the meridional and vertical components are significantly stronger than the climatology. The meridional EPD, most likely caused by waves propagating southward at $10^{\circ} \mathrm{N}$, largely contributes to the deceleration of the QBO jet in the SH. The vertical EPD, presumably caused by waves propagating vertically at $70 \mathrm{hPa}$ between 0 and $15^{\circ} \mathrm{N}$, largely contributes to the deceleration of the QBO jet in the NH.

To investigate whether the anomalously strong EPF-z at $70 \mathrm{hPa}$ in Fig. 5 originates in the equatorial region, Fig. 6 shows the EPF and EPD for the $L_{\mathrm{w}}$ waves, which are westward-propagating low-frequency waves, in the troposphere and for the Rossby waves in the lower stratosphere. Here, we focus on January and February 2016 when EPF-z is strong and moderate, respectively. In January 2016 (Fig. 6a), there are three potential source regions of the Rossby waves: (i) $5^{\circ} \mathrm{N}-10^{\circ} \mathrm{S}$ at $120-400 \mathrm{hPa}$ (equatorial source), (ii) $15-$ $25^{\circ} \mathrm{S}$ at $200-350 \mathrm{hPa}$ ( $\mathrm{SH}$ source), and (iii) $20-25^{\circ} \mathrm{N}$ and 250-450 hPa ( $\mathrm{NH}$ source), considering that the positive EPD region should be a source region of westward- and upwardpropagating waves. First, from the equatorial source, wave activity propagates upward and northward up to $\sim 120 \mathrm{hPa}$. There, it seems to merge with the wave activity from the $\mathrm{NH}$ sources, while part of it propagates upward to the NH stratosphere near $0-15^{\circ} \mathrm{N}$. Second, some of the waves from the $\mathrm{SH}$ source propagate to the $\mathrm{SH}$ stratosphere after depositing a large amount of negative momentum between 100 and $70 \mathrm{hPa}$, and others propagate to the NH stratosphere. Third, the wave activity from the NH source does not seem to propagate upward. In addition to the three source regions, there might be other source regions at midlatitudes, so the propagation from the midlatitudes in both hemispheres also needs to be considered. It is shown that the wave activity from the $\mathrm{NH}$ (SH) midlatitude propagates into the equatorial stratosphere at the altitude range above $100 \mathrm{hPa}(200 \mathrm{hPa})$. The behavior in February 2016 is generally similar to that in January 2016. In summary, the strong EPF-z for Rossby waves at $70 \mathrm{hPa}$ is attributed to both the equatorially generated waves and the waves propagating from the $\mathrm{NH}$ and the $\mathrm{SH}$.

Figure 7 shows the EPF and EPD for the MRG waves in October, November, and December 2015, as well as February 2016, when MRG waves significantly contribute to the negative EPD. The vertical profiles of EPF-y at $10^{\circ} \mathrm{N}$ and $10^{\circ} \mathrm{S}$ are plotted on the right and left side of each panel, and the meridional distribution of the EPF- $\mathrm{z}$ at $70 \mathrm{hPa}$ is plotted at the bottom of each panel. In Fig. 7, we will focus on the altitude near $40 \mathrm{hPa}$, where the wave forcing is directly related to the QBO disruption, although strong negative wave forcing also exists in the upper stratosphere. In October 2015 (Fig. 7a), all the wave forcing is similar to the climatology except for 

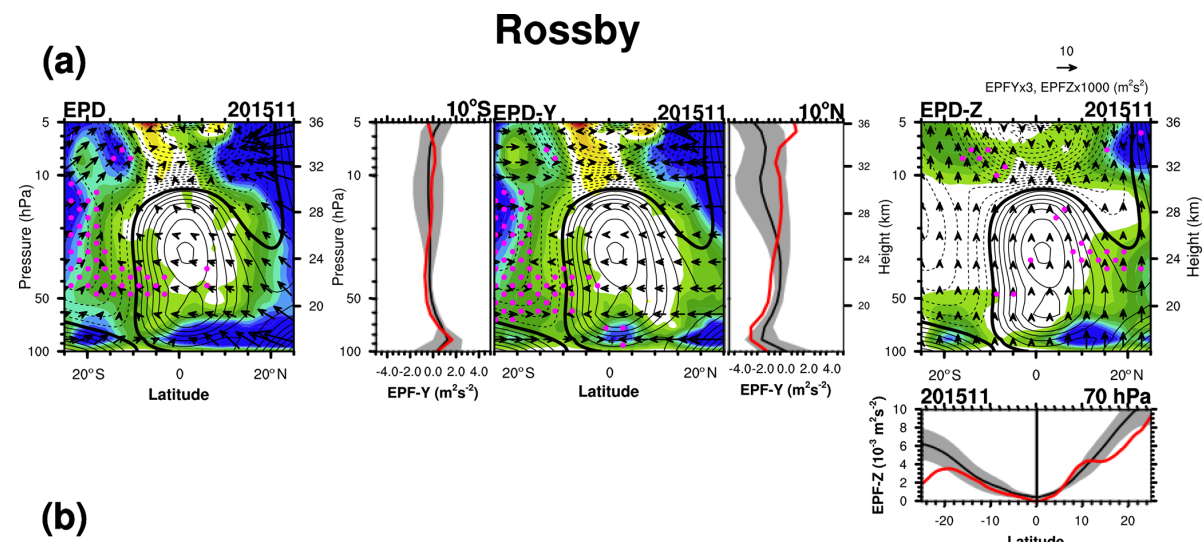

(b)
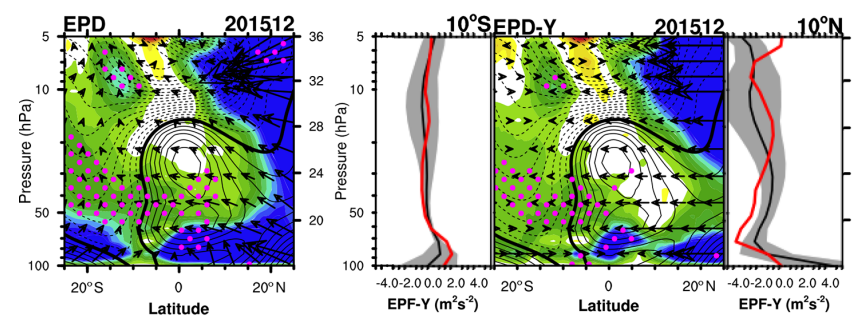

(c)
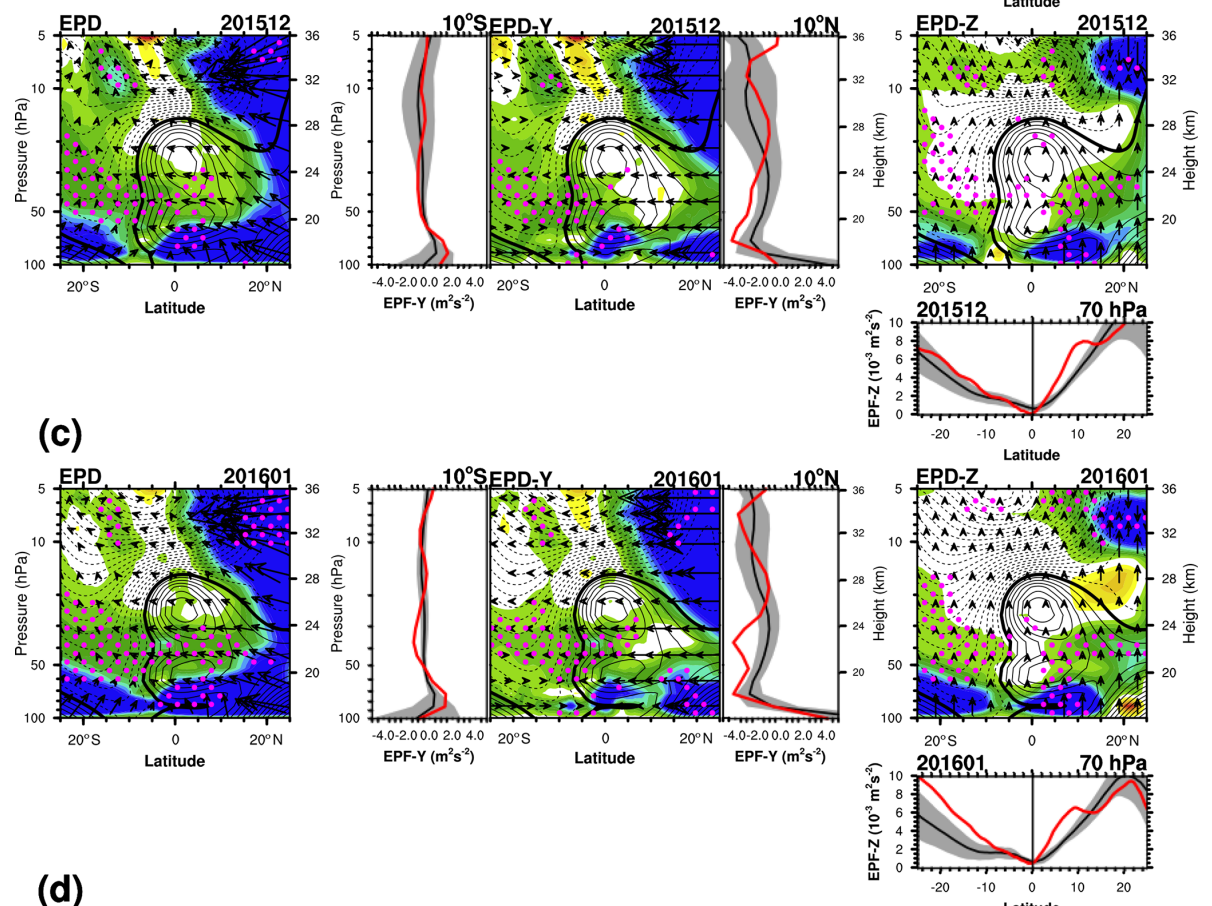

(d)
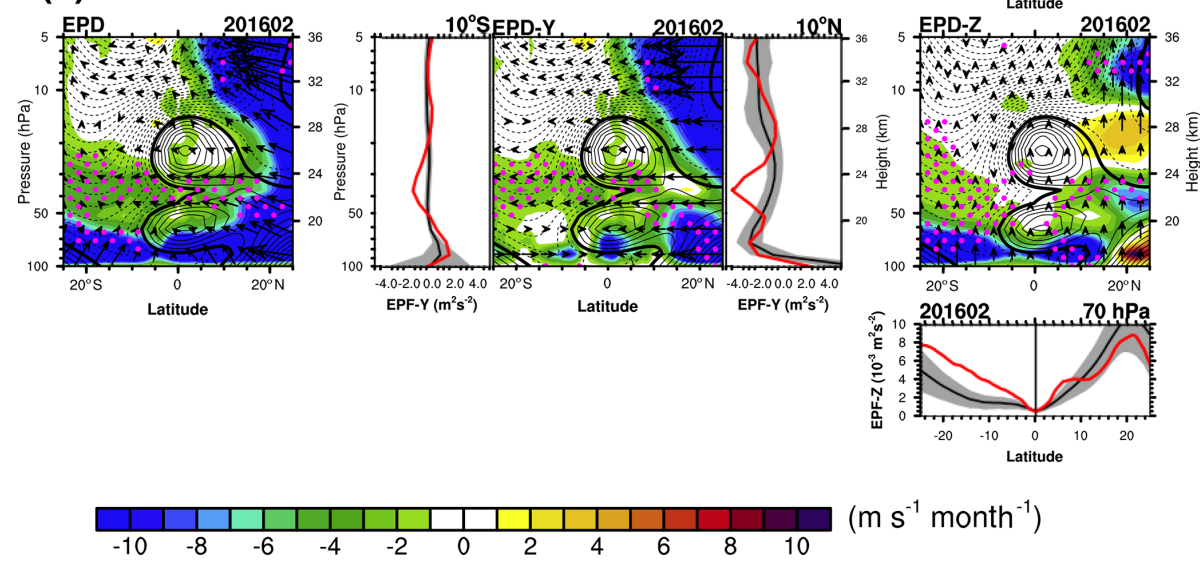

Figure 5. Latitude-height cross sections of the (first column) EP flux (vectors) divided by air density and EP flux divergence (EPD, shading) for the Rossby waves, (second column) their meridional component, and (third column) their vertical component in (a) November 2015, (b) December 2015, (c) January 2016, and (d) February 2016. The panel on the left (right) side of the meridional component represents the meridional EP fluxes at $10^{\circ} \mathrm{S}\left(10^{\circ} \mathrm{N}\right)$, and the panel under the vertical component represents the vertical EP flux at $70 \mathrm{hPa}($ red lines for each month and black lines for their monthly climatology with $\pm 1 \mathrm{SD}$; gray shading). Positive (negative) zonal winds are plotted with solid (dashed) lines with a contour interval of $2 \mathrm{~m} \mathrm{~s}^{-1}$, and thick contour lines denote a zero zonal wind speed. The magenta stippled pattern represents a region where the EPD is algebraically smaller (more negative) than the climatology by more than its SD. 


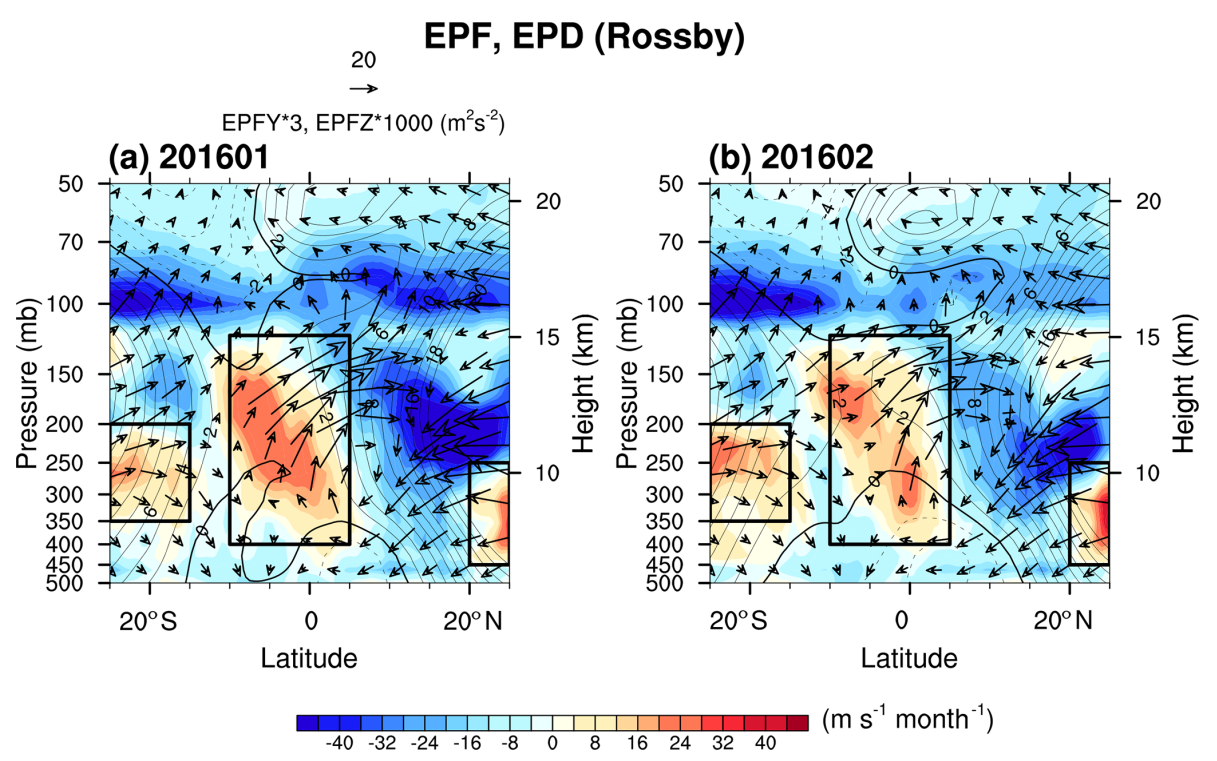

Figure 6. Latitude-height cross sections of the EP flux (vectors) divided by air density and EP flux divergence (shading) for the Rossby waves in (a) January 2016 and (b) February 2016. Note that below $100 \mathrm{hPa}$, the $L_{\mathrm{W}}$ waves $(\omega \leq 0.4 \mathrm{cpd}$ and $-20 \leq k<0)$ are assumed to be Rossby waves. Black boxes denote the three potential source regions.

the MRG waves (Fig. S3); the negative MRG wave forcing is stronger than the climatology by more than $1 \sigma$ at $50 \mathrm{hPa}$ at $0-5^{\circ} \mathrm{S}$ (indicated by the magenta dots). Given the dominant upward propagation in the lower to middle stratosphere, the MRG waves exerting negative forcing near $50 \mathrm{hPa}$ at 0 $5^{\circ} \mathrm{S}$ seem to propagate from $60-80 \mathrm{hPa}$ and $5-10^{\circ} \mathrm{S}$ where the positive EPD exists. While the increase in the meridional $\mathrm{EPF}$ at $5-10^{\circ} \mathrm{S}$ near $70 \mathrm{hPa}$ is somewhat unclear in the EPF-y at $10^{\circ} \mathrm{S}$, it is clear in the EPF-y at 7 and $5^{\circ} \mathrm{S}$, showing a noticeable increase toward the Equator compared to the climatology (not shown). The increase in the vertical $\mathrm{EPF}$ at $60-80 \mathrm{hPa}$ is evident in the EPF-z at $70 \mathrm{hPa}$, which is greater than the climatology by more than $1 \sigma$ at $10^{\circ} \mathrm{S}-$ $0^{\circ}$. It is worthwhile to note that there is a positive EPD over $5-10^{\circ} \mathrm{N}$ at $70 \mathrm{hPa}$ as well, implying that $5-10^{\circ} \mathrm{N}$ and 60 $80 \mathrm{hPa}$ might be another source region for MRG wave generation. However, the increases in the EPF-z at $70 \mathrm{hPa}$ and EPF-y at $5-10^{\circ} \mathrm{N}$ are less significant compared to the climatology. In November 2015 (Fig. 7b), a pattern similar to that in October 2015 appears, but with an increase in the magnitude of the negative EPD at 40-60 hPa within $5^{\circ} \mathrm{N}-\mathrm{S}$ and the EPF-y at $10^{\circ} \mathrm{S}$ at $50-80 \mathrm{hPa}$. The strong EPD at $0-10^{\circ} \mathrm{S}$ and $40-60 \mathrm{hPa}$ most likely originates from the strong EPF-y at $10^{\circ} \mathrm{S}$ at $60-80 \mathrm{hPa}$ and EPF-z at $70 \mathrm{hPa}$ at $5-15^{\circ} \mathrm{S}$. In December 2015 (Fig. 7c) and February 2016 (Fig. 7d), strong negative EPD, equatorward EPF-y at $10^{\circ} \mathrm{S}$, and upward EPF$\mathrm{z}$ at $70 \mathrm{hPa}$ are still evident.

According to this analysis, we conclude that MRG waves decelerate the QBO jet core $\left(5^{\circ} \mathrm{N}-5^{\circ} \mathrm{S}\right)$ at the onset of the QBO disruption given that the negative zonal wind tendency from October to November 2015 is partly attributed to the anomalously strong MRG wave forcing: the MRG wave forcing at $40 \mathrm{hPa}$ in October and November 2015 is -0.4 and $-0.6 \mathrm{~m} \mathrm{~s}^{-1}$ per month, respectively, and the QBO jet core is reduced to $12.3,11.1$, and $8.2 \mathrm{~m} \mathrm{~s}^{-1}$ from October to December 2015 (Fig. 4; Table 1). The positive EPD at $60-80 \mathrm{hPa}$ between 5 and $15^{\circ} \mathrm{S}$ by MRG is much greater than the climatology for both the meridional and vertical components. From $60-80 \mathrm{hPa}$ and $5-15^{\circ} \mathrm{S}$, the waves propagate equatorward and upward, reaching $40-50 \mathrm{hPa}$ near the Equator (Fig. 7a and b), implying that the region of $60-90 \mathrm{hPa}$ at 5$15^{\circ} \mathrm{S}$ (boxed region in Fig. 8) is a possible location where the MRG waves are mainly excited.

Coy et al. (2017) have investigated whether baroclinic instability led to the easterly wind development in February 2016, although they did not investigate the possibility of wave generation and/or amplification by baroclinic and/or barotropic instability for the period before February 2016. As MRG waves contribute significantly to the negative EPD from October to November 2015 (Figs. 3, 4, and 7), it is worth examining whether baroclinic or barotropic instability is a likely source of MRG waves (Andrews and McIntyre, 1976; Garcia and Richter, 2019) in October and November 2015.

Figure 8 presents the monthly mean $\bar{q}_{\phi}$ (Fig. 8a and b), the number of grids for which the daily mean $\bar{q}_{\phi}$ is negative (Fig. 8c) along with its climatology, and daily mean EPD for the MRG waves (Fig. 8d) in October and November 2015. The monthly mean $\bar{q}_{\phi}$ in the boxed region has small positive values in October 2015 (Fig. 8a) and November 2015 (Fig. 8b). In Fig. 8c, however, 22 and $25 \mathrm{~d}$ during October and November, respectively, have negative $\bar{q}_{\phi}$ values by at least 


\section{MRG}

(a)

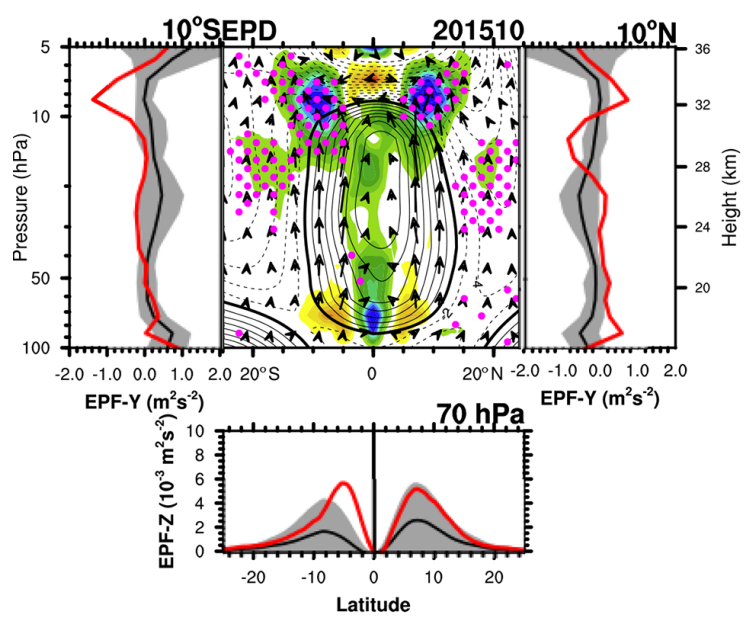

(c)

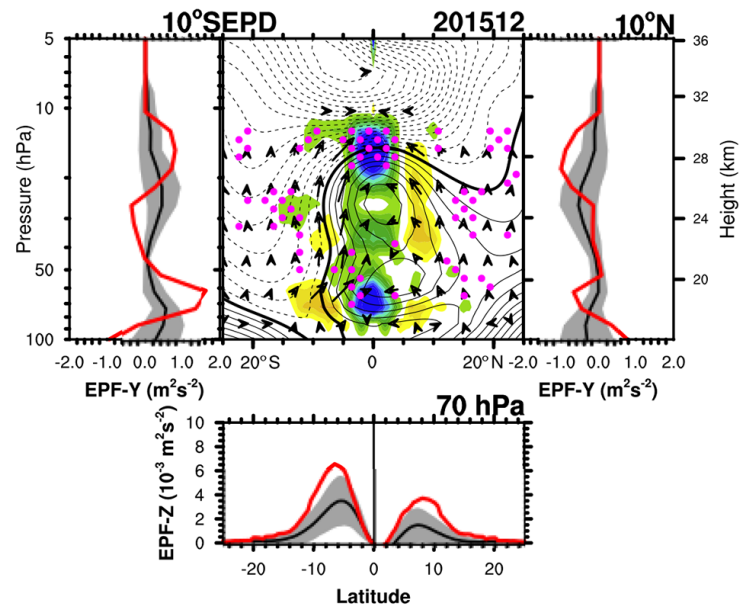

(b)

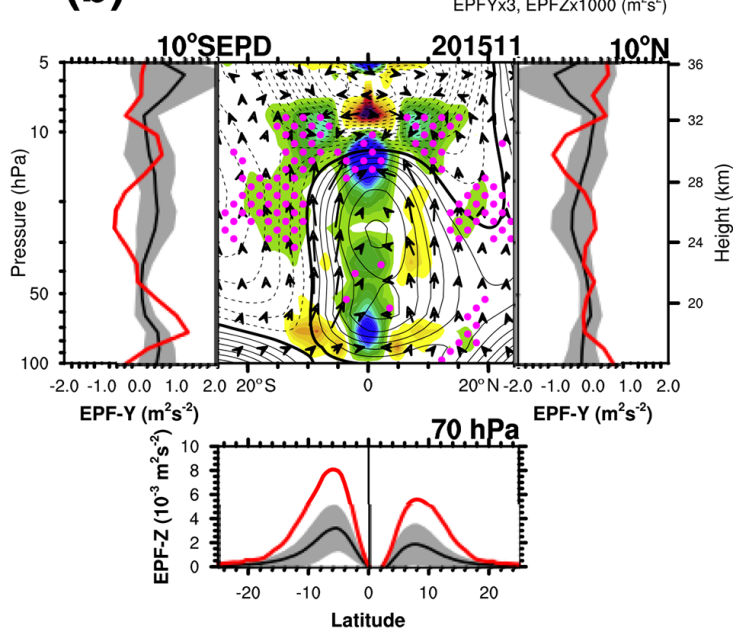

(d)

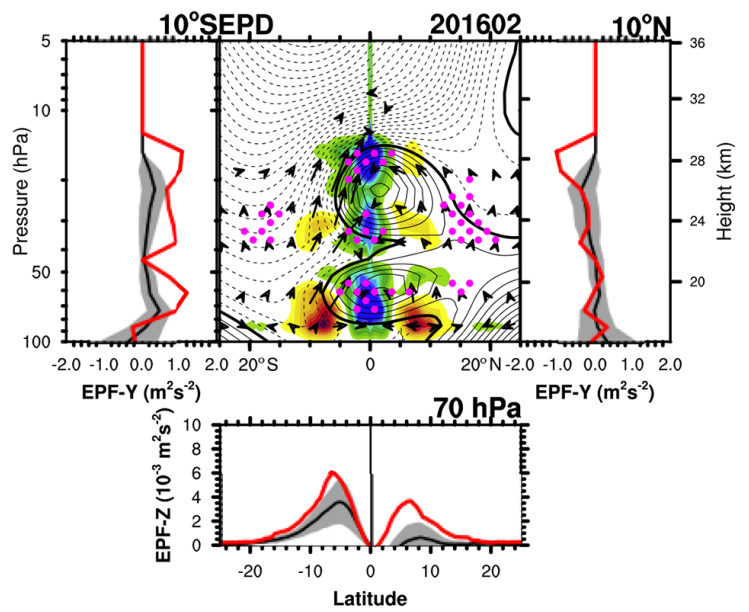

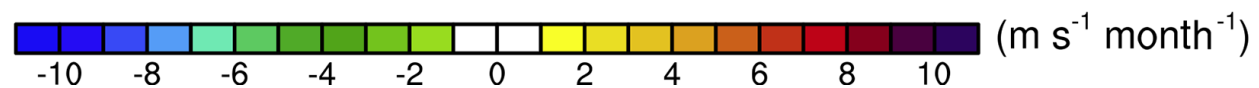

Figure 7. Latitude-height cross sections of the EP flux (vectors) and EP flux divergence (EPD, shading) for the MRG waves in (a) October 2015, (b) November 2015, (c) December 2015, and (d) February 2016. The panel on the left (right) side of the EPD represents the meridional EP fluxes at $10^{\circ} \mathrm{S}\left(10^{\circ} \mathrm{N}\right)$, and the panel under the EPD represents the vertical EP flux at $70 \mathrm{hPa}$ (red lines for each month and black lines for their monthly climatology with $\pm 1 \mathrm{SD}$; gray shading). Positive (negative) zonal winds are plotted with solid (dashed) lines with a contour interval of $2 \mathrm{~m} \mathrm{~s}^{-1}$, and thick contour lines denote a zero zonal wind speed. The magenta stippled pattern represents a region where the EPD is algebraically smaller (more negative) than the climatology by more than its SD. Here, EPF and EPD are multiplied by 8 and 4 , respectively.

one point within the boxed region, which satisfies a necessary condition for baroclinic instability dominated by barotropic instability (not shown). The number of negative $\bar{q}_{\phi}$ days is much larger than the climatology (11 and 19d with SDs of 11 and $7 \mathrm{~d}$ in October and November, respectively). When the number of grids with $\bar{q}_{\phi}<0$ increases, the daily mean EPD becomes large (e.g., 1-11 October, 21-25 October, and 25-
30 November). This suggests that barotropic instability in the boxed region is a possible source for generating the anomalously strong MRG waves. The MRG waves generated by the barotropic instability in the narrow westerly jets accelerate the zonal wind off the Equator and decelerate the zonal wind near the Equator, reducing the curvature and thus the instability, which indicates that the MRG waves respond to the QBO 

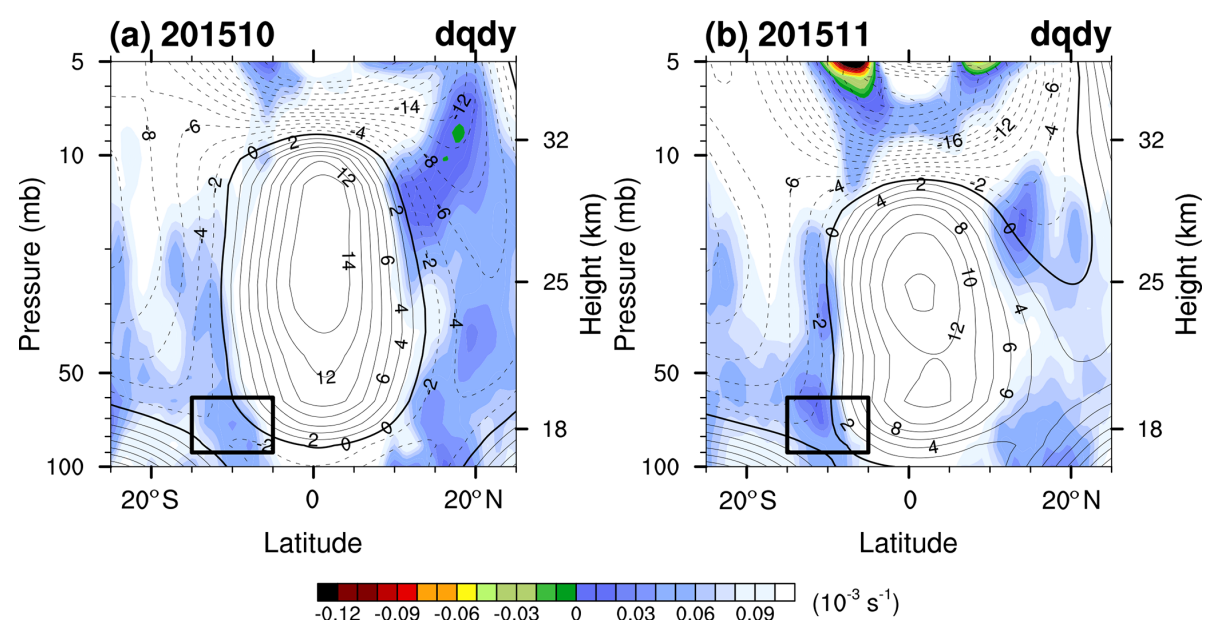

(c) $201510-201511$ $5^{\circ}-15^{\circ} \mathrm{S}, 60-90 \mathrm{hPa}(61$ grids $)$
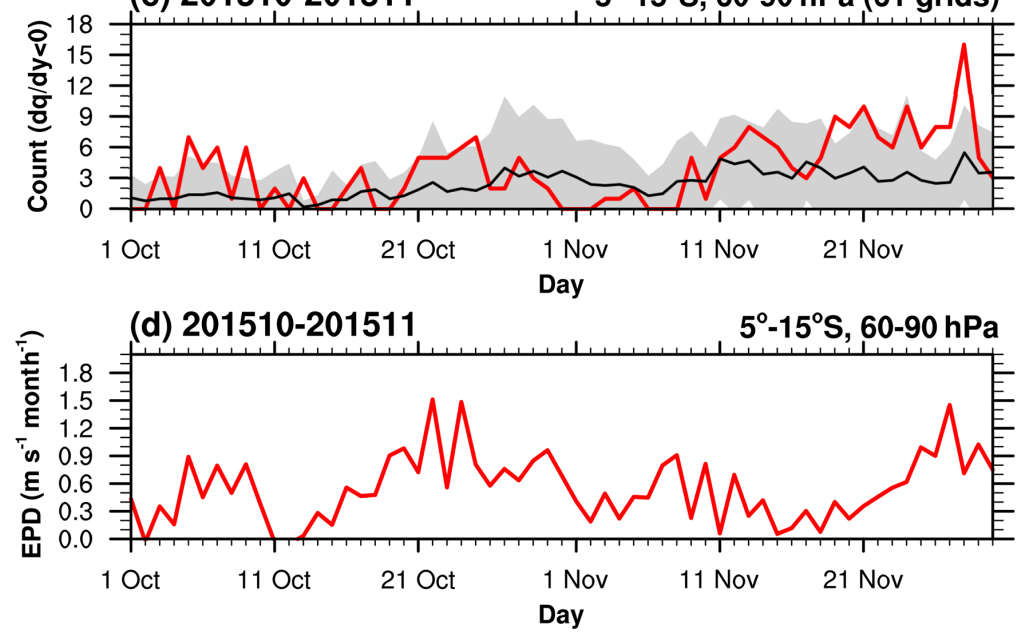

Figure 8. Latitude-height cross sections of the monthly mean $\bar{q}_{\phi}$ (shading) superimposed on the zonal-mean zonal wind (contour) in (a) October 2015 and (b) November 2015. Positive (negative) zonal winds are plotted with solid (dashed) lines with a contour interval of $2 \mathrm{~ms}^{-1}$, and thick contour lines denote a zero zonal wind speed. Daily time series of the (c) number of grids for which daily mean $\bar{q}_{\phi}\left(\mathrm{s}^{-1}\right)$ is negative in the boxed region $\left(5-15^{\circ} \mathrm{S}, 60-90 \mathrm{hPa}\right)$ and (d) those of the EPD for the MRG waves averaged over the boxed region in October-November 2015 (red). Black lines in (c) are for the climatology with \pm 1 SD (gray shading).

wind system (Garcia and Richter, 2019). However, as the deceleration of the jet core is important in the QBO disruption, such behavior may play an important role in preconditioning the background wind. It should be noted that the barotropic instability does not seem to be an exclusive source of MRG waves because there are precedent WQBO cases having considerably negative $\bar{q}_{\phi}$ without significant enhancement in the wave generation (e.g., 2010, 1987, and 1982). Therefore, further studies on the source of the MRG waves should be done in the future. It is also interesting that $\bar{q}_{\phi}$ shows large negative values at the upper stratosphere $(\sim 5 \mathrm{hPa})$ where the zonal wind curvature is large in association with a strong westerly jet (Hamilton, 1984). Nevertheless, it is unlikely that the MRG waves generated at $5 \mathrm{hPa}$ affect the QBO disruption as the upward-propagating MRG waves (i.e., vertical EPF $>0$ ) are dominant in the stratosphere, and the strong easterlies between 5 and $10 \mathrm{hPa}$ inhibit the propagation of the MRG waves.

We found in the previous figures (Figs. 5 and 6) that the increased Rossby wave forcing in the stratosphere partly originates from the equatorial troposphere. Therefore, in Fig. 9, we examine the zonal mean precipitation in the equatorial troposphere to identify convective activity using MERRA-2 data. Overall, the zonal mean precipitation from November 2015 to February 2016 is stronger than the climatology at $5^{\circ} \mathrm{N}-5^{\circ} \mathrm{S}$. It is greater than the climatology by more than $1 \sigma$ from November to December 2015 (Fig. 9a and b). In February 2016 (Fig. 9d), the precipitation is much stronger than the climatology between $5^{\circ} \mathrm{N}$ and $10^{\circ} \mathrm{S}$ by more than $3 \sigma$. The maximum precipitation is slightly shifted southward in 


\section{Precipitation}

(a) 201511

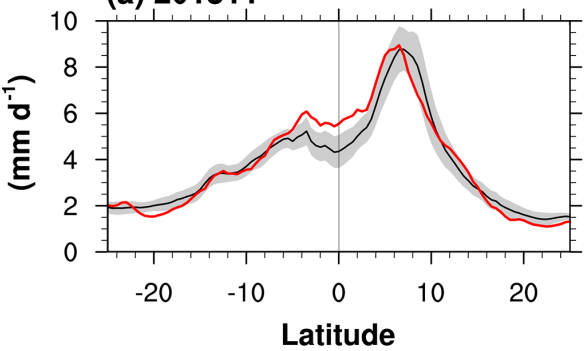

(c) 201601

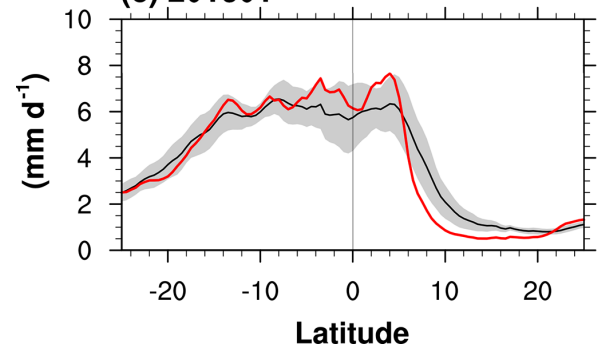

(b) 201512

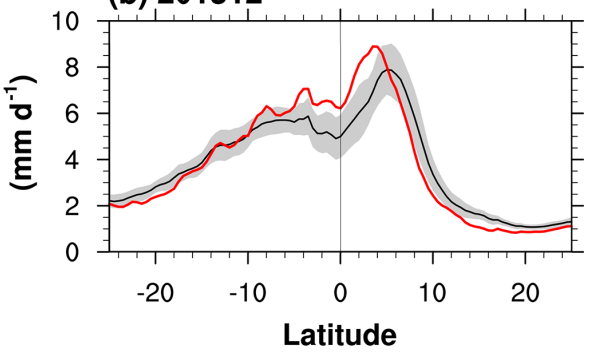

(d) 201602

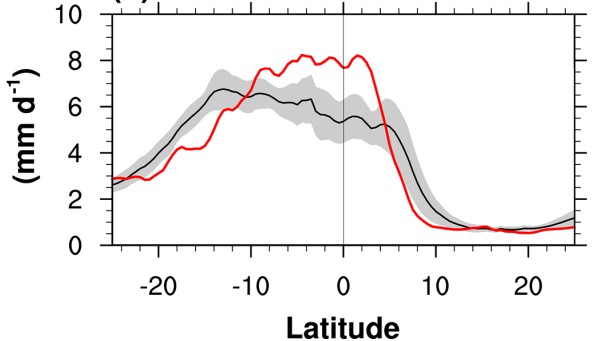

Figure 9. Zonal mean precipitation from MERRA-2 in (a) November 2015, (b) December 2015, (c) January 2016, and (d) February 2016 (red) and their monthly climatology (black) with \pm 1 SD (gray shading).

December-January-February (DJF), following the location of the inter-tropical convergence zone (ITCZ).

We further check whether the precipitation spectrum related to each equatorial wave type is enhanced during the disruption. Figure 10 illustrates the power spectrum of the precipitation data from MERRA-2 divided by background spectrum averaged over $10^{\circ} \mathrm{N}-10^{\circ} \mathrm{S}$ for both the symmetric and antisymmetric components. The background spectrum is obtained by applying 1-2-1 smoothing to the base-10 logarithm of the raw spectrum (separately for the symmetric and antisymmetric spectrum) in wavenumber and frequency 40 and 10 times, respectively, and applying the base-10 exponential again to the smoothed spectrum (Chao et al., 2009). If the raw spectrum divided by the background spectrum is greater than 1.4, it is considered statistically significant at the $95 \%$ level for 41 degrees of freedom (i.e., corresponding to the number of latitude grid cells from $10^{\circ} \mathrm{N}$ to $10^{\circ} \mathrm{S}$ ) (Wheeler and Kiladis, 1999).

The area where the precipitation spectrum is greater than the climatology by more than $1 \sigma$, which is denoted by a stippled pattern, widens from November 2015 to February 2016, indicating that not only the mean value but also the variability of the convection significantly increases during the disruption. The spectra related to Rossby waves in the symmetric spectrum $(k=-10-0, \omega=0-0.15 \mathrm{cpd})$ are statistically significant throughout the period, suggesting that the convective activity in the troposphere is the probable source for Rossby waves. However, the waves in the low-frequency spectra have less possibility to propagate upward into the stratosphere due to their slow vertical group velocity (Yang et al., 2011). In November 2015 (Fig. 10a) and December 2015 (Fig. 10b), the spectra related to MRG waves in the antisymmetric component $(k=-9$ and $\omega=0.12 ; k=-5$ and $\omega=0.28)$ are statistically significant and their amplitude is stronger than the climatology by more than $1 \sigma$. However, they are less likely to be the primary source of the anomalously negative MRG wave forcing in the stratosphere given that the EPF-z for MRG waves greater than the climatology only appears at an altitude above $70 \mathrm{hPa}$ (Fig. 7). It is also interesting that the peaks related to Kelvin waves $(k=0-10$ and $\omega=0-0.25$ ) increase from November 2015 (Fig. 10a) to February 2016 (Fig. 10d), consistent with the increasing EPF-z at $70 \mathrm{hPa}$ (see Fig. S4) and the resultant EPD (Fig. 2) during the disruption. The enhanced Kelvin wave activity during the disruption period was caused by the enhanced convective activity associated with strong El Niño events ( $\mathrm{Li}$ et al., 2020). Overall, we found that convectively coupled equatorial waves are enhanced during the QBO disruption, which seem to be associated with El Niño.

To validate the realism of the MERRA-2 precipitation data, we additionally calculate the space-time spectra of precipitation provided by TRMM in Fig. S8. The key features are present in TRMM, but the amplitude is larger than that of MERRA-2, possibly attributed to the finer resolution. Note that TRMM data are available in a shorter period (19982016) than the MERRA-2 data (1980-2016), so only 5 years are included as WQBO climatology in Fig. S8. As in the MERRA-2 data, there is a significant increase in the precipitation from TRMM during January and February 2016 (Fig. S8) compared to the climatology. 


\section{Precipitation (PSD/Background, $10^{\circ} \mathrm{N}-10^{\circ} \mathrm{S}$ )}

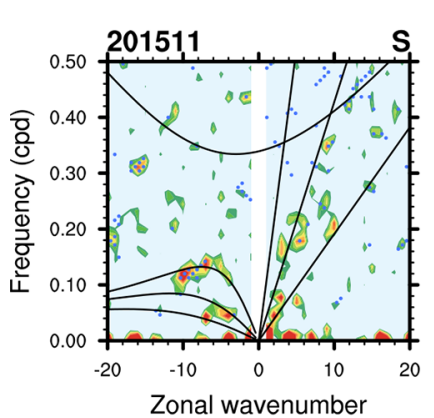

(a)
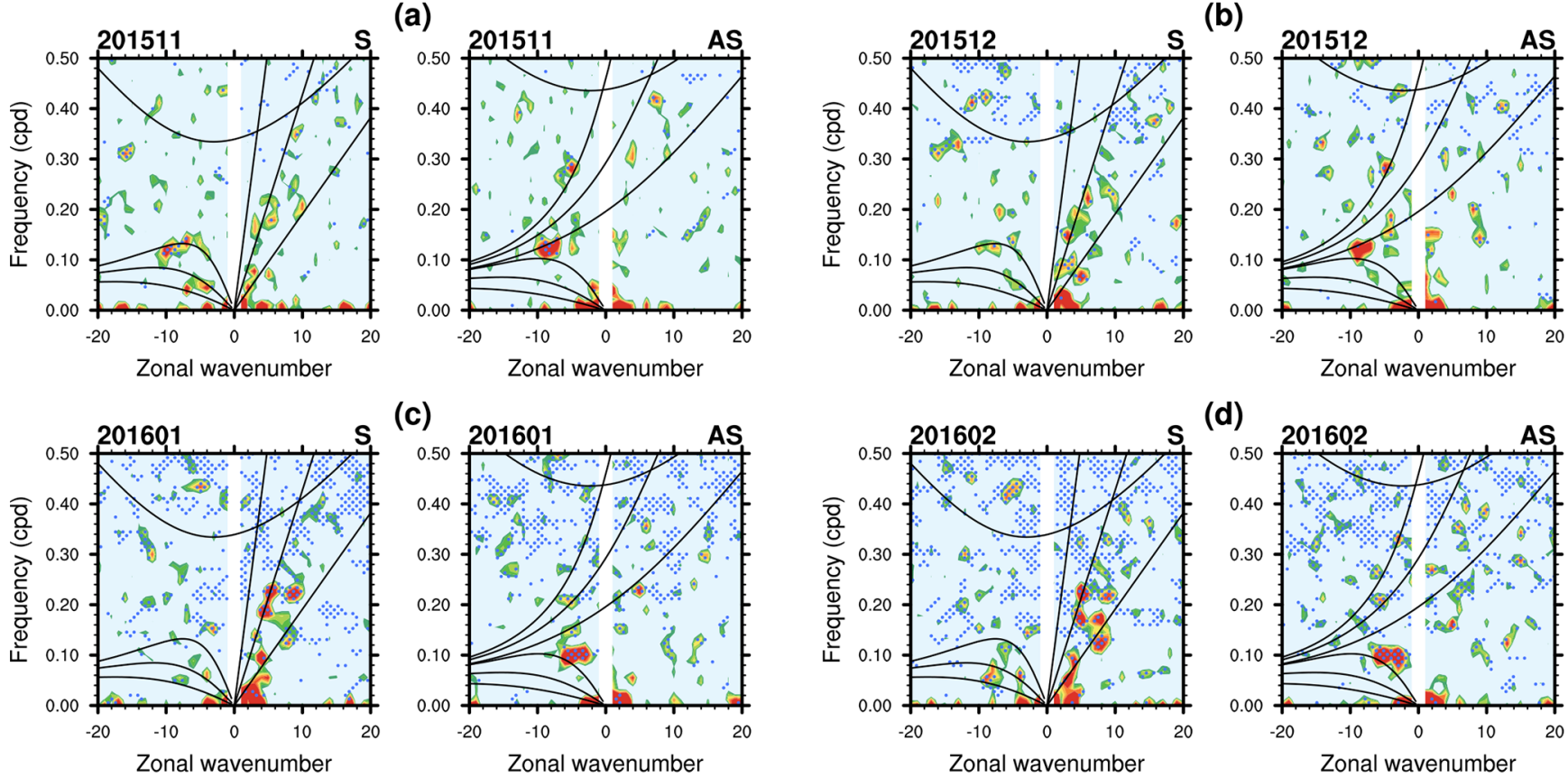

(c)
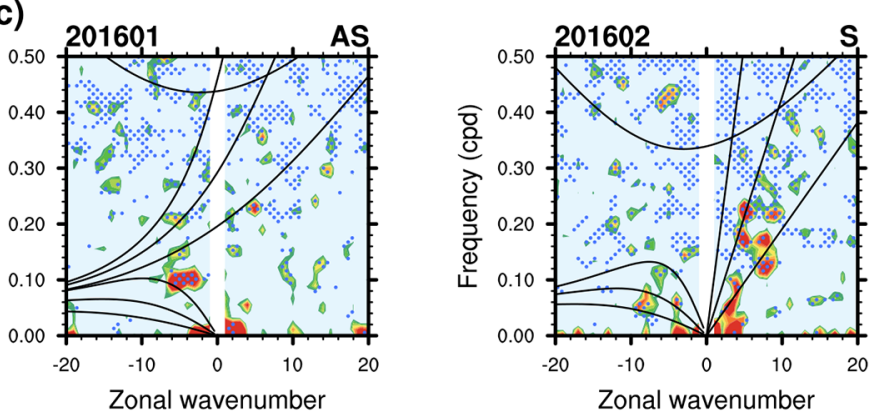

(d)
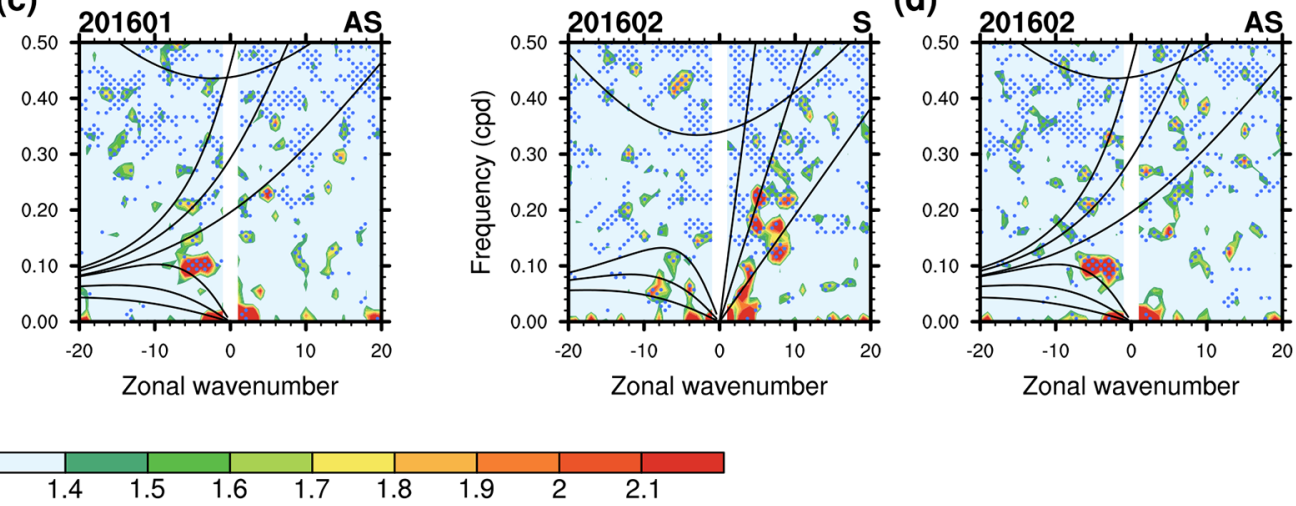

Figure 10. Power spectral density for the MERRA-2 precipitation divided by the background spectrum (see text for details) as a function of zonal wavenumber and frequency for (left) symmetric and (right) antisymmetric components averaged over $10^{\circ} \mathrm{N}-10^{\circ} \mathrm{S}$ in (a) November 2015, (b) December 2015, (c) January 2016, and (d) February 2016. When the ratio between the raw power and the background power is larger than 1.4 , it is considered a statistically significant spectrum at the $95 \%$ level. The blue stippled pattern denotes a spectrum on which the power is stronger than the climatology by more than its SD. Thick solid lines denote the theoretical dispersion lines of each equatorial wave for the equivalent depth of $h=8,40$, and $240 \mathrm{~m}$, although only the $h=8 \mathrm{~m}$ line is shown for IG waves.

\subsection{Contribution of inertia-gravity waves}

Figure 11 shows EPF vectors and EPD for the IG waves, together with the meridional distribution of EPF-z at $70 \mathrm{hPa}$, from November 2015 to February 2016. In this figure, the vertical cross section of EPF-y is not shown because EPF-z dominates the total EPF. EPF-z here is the net EPF of eastward and westward IG waves, so the positive EPF-z indicates stronger westward EPF than the eastward one given the dominant upward propagation in the stratosphere. Anomalously strong negative wave forcing exists at $10-20 \mathrm{hPa}$ near the Equator throughout the period. In November 2015 (Fig. 11a), negative wave forcing is anomalously strong at $40-80 \mathrm{hPa}$ near the Equator $\left(0-5^{\circ} \mathrm{S}\right)$, influencing the deceleration and the downward shift of the WQBO jet core in the following months. The strong negative forcing is likely attributable to the strong vertical $\mathrm{EPF}$ at $70 \mathrm{hPa}$, which is greater than the climatology by more than $1 \sigma$. In December 2015 (Fig. 11b) and January 2016 (Fig. 11c), it is shown that the negative wave forcing at $40-80 \mathrm{hPa}$ near the Equator and the westward EPF-z at $70 \mathrm{hPa}$ at $10^{\circ} \mathrm{N}-10^{\circ} \mathrm{S}$ are anomalously strong, as in November 2015. In February 2016, negative wave forc- ing exists at $40 \mathrm{hPa}$ and $0-5^{\circ} \mathrm{S}$ without significance, while the negative wave forcing near the top of the lower jet is significant. From November 2015 to February 2016, the strong westward IG wave forcing is mainly induced by the vertical EPF penetrating into the stratosphere from the troposphere. Then why do the westward IG waves at $70 \mathrm{hPa}$ show a noticeable increase during the disruption?

To answer this question, we show the vertical EPF for $H_{\mathrm{e}}+H_{\mathrm{w}}$ waves (approximately for IG waves) at the source level (140 hPa; Sect. 2.3) from November 2015 to February 2016 in Fig. 12. The eastward and westward waves have similar magnitudes in November 2015. However, the westwardpropagating waves start to dominate the vertical EPF from December 2015. In January and February 2016, the vertical $\mathrm{EPF}$ at $140 \mathrm{hPa}$ is greater than the climatology by more than $1 \sigma$ at $10^{\circ} \mathrm{N}-10^{\circ} \mathrm{S}$. The stronger westward EPF-z at $140 \mathrm{hPa}$ from December 2015 to February 2016 suggests that the preference for westward-propagating waves at $70 \mathrm{hPa}$ stems from the source level ( $140 \mathrm{hPa}$; Sect. 2.3$)$, except in November 2015 .

Figure 13 illustrates the power spectral density of the precipitation in a phase-speed spectrum of the $H_{\mathrm{e}}+H_{\mathrm{w}}$ waves 

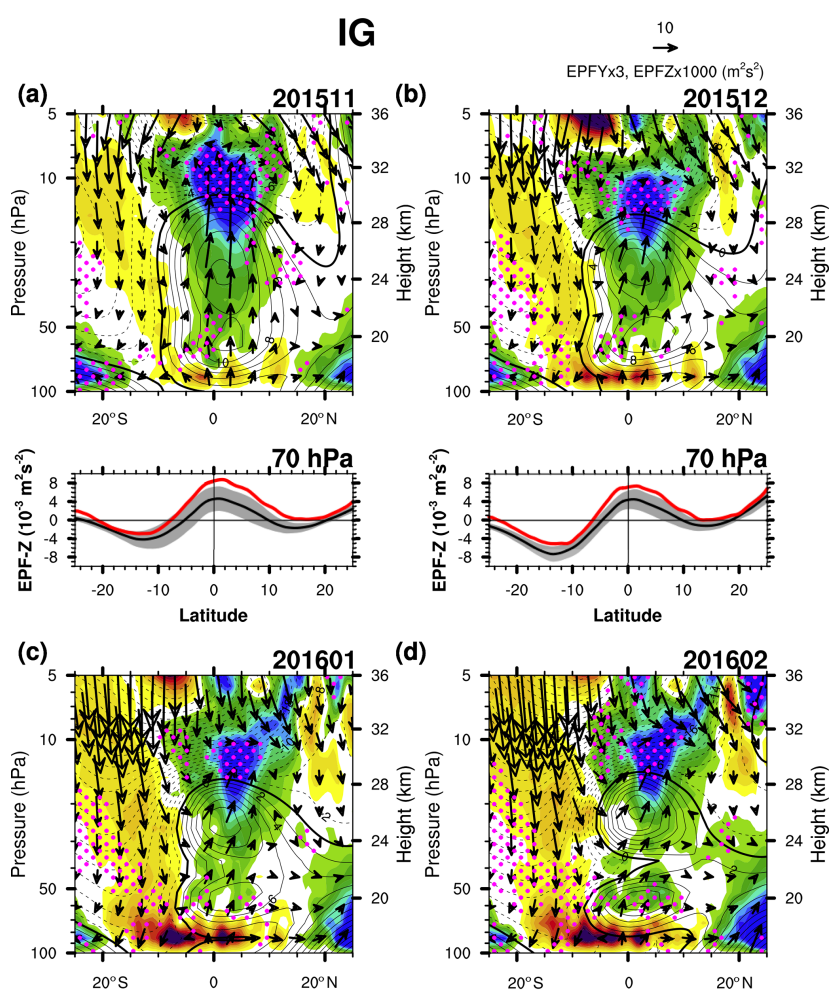

(d)
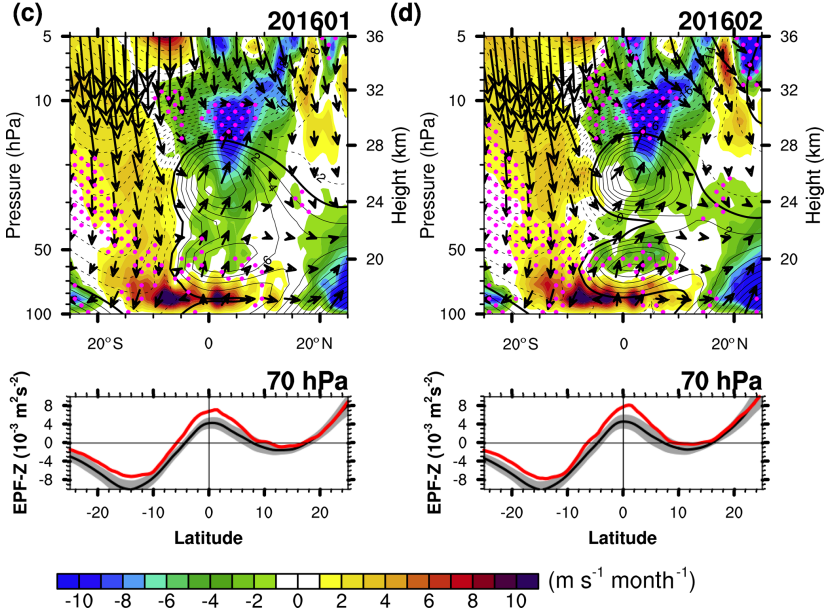

Figure 11. Latitude-height cross sections of the EP flux (vectors) divided by air density and EP flux divergence (shading) for the IG waves (multiplied by 4) with the (bottom) vertical EP flux for the IG waves at $70 \mathrm{hPa}$ in (a) November 2015, (b) December 2015, (c) January 2016, and (d) February 2016 (red), along with their monthly climatology (black) with \pm 1 SD (gray shading). Positive (negative) zonal winds are plotted with solid (dashed) lines with a contour interval of $2 \mathrm{~m} \mathrm{~s}^{-1}$, and thick contour lines denote a zero zonal wind speed. The magenta stippled pattern represents a region where the EPD is algebraically smaller (more negative) than the climatology by more than its SD. Here, EPF and EPD are multiplied by 8 and 4, respectively.

from November 2015 to February 2016 along with the climatology. The precipitation spectrum is classified as eastwardpropagating (westward-propagating) waves when the phase speed is larger (smaller) than the zonal wind at the source level. The double-sided arrows represent the zonal wind range between the source level $(140 \mathrm{hPa})$ and $70 \mathrm{hPa}$ in each month, indicating the phase-speed range of the critical-level filtering. In November 2015 (Fig. 13a), the zonal wind at the source level is near zero, so the precipitation spectrum has a similar amplitude between the eastward and westward waves. However, the eastward waves are almost filtered out due to the positive vertical wind shear between 140 and $70 \mathrm{hPa}$ (see Fig. 1). This feature is different from the climatology, which has stronger westward waves than eastward waves at the source level. As most of the pronounced westward waves are filtered out due to the negative vertical wind shear (see Fig. 1), the remaining spectrum at $70 \mathrm{hPa}$ in November 2015 has more westward waves than the climatology. In December 2015 (Fig. 13b), the wave characteristics at the source level during the disruption agree well with the climatology - that is, stronger westward waves than eastward waves and a similar magnitude of westerly winds at the source level. However, both a larger magnitude of the precipitation spectrum and the narrower critical-level filtering range for the westward waves result in stronger westward momentum flux at $70 \mathrm{hPa}$ during the disruption than the climatology. From January 2016 (Fig. 13c), (i) the westerly anomaly at the source level, (ii) strong precipitation spectrum, and (iii) decreased criticallevel filtering of the westward waves induce a stronger westward momentum flux at $70 \mathrm{hPa}$. The presence of stronger westerlies at the source level than the climatology during the disruption becomes apparent in February 2016, leading to the strongest westward momentum flux at the source level. The same conclusion is obtained when the eastward and westward waves are analyzed separately (Fig. S9). Figure 13 suggests that strong westward IG waves at $70 \mathrm{hPa}$ during the disruption are largely attributed to the reduced critical-level filtering of westward waves in November 2015, while in December 2015, those are attributed to both enhanced convection and the decreased critical-level filtering. In January and February 2016, the westerly anomaly at the source level and the reduced filtering of westward waves play an important role in the increased westward IG wave forcing, along with stronger convection.

Kawatani et al. (2019) showed stronger westward wave forcing between 40 and $70 \mathrm{hPa}$ during El Niño than during La Niña in their Model for Interdisciplinary Research on Climate-Atmospheric General Circulation Model (MIROCAGCM) simulation. They explained that larger westward forcing is due to the strong westward EPF in the upper troposphere-lower stratosphere (UTLS), which is attributed to enhanced convective activity with $-10<c<10 \mathrm{~ms}^{-1}$ (where $c$ is the phase speed) and less critical-level filtering of the IG waves during El Niño than during La Niña. Less filtering of IG waves during El Niño is due to the westerly anomalies in the lower stratosphere, which is supported by the fact that the zonal wind near the Equator becomes more westerly during El Niño than during La Niña (Barton and McCormack, 2017). This is consistent with our results, implying that the enhanced wave source (i.e., convection) and the propagation conditions favorable for westward IG waves in the current study are presumably associated with the strong El Niño condition. 
EPF-Z at $140 \mathrm{hPa}(\mathrm{He}+\mathrm{Hw})$

(a) 201511

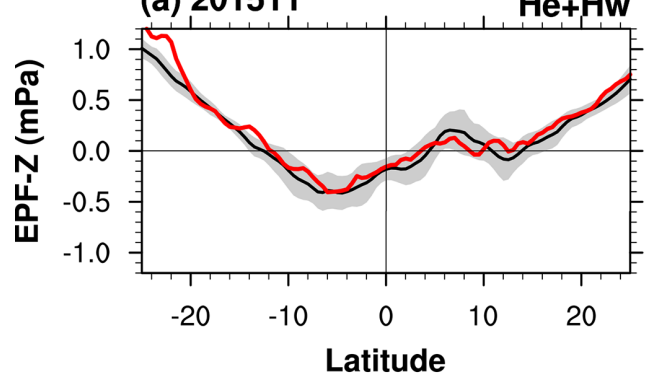

(c) 201601

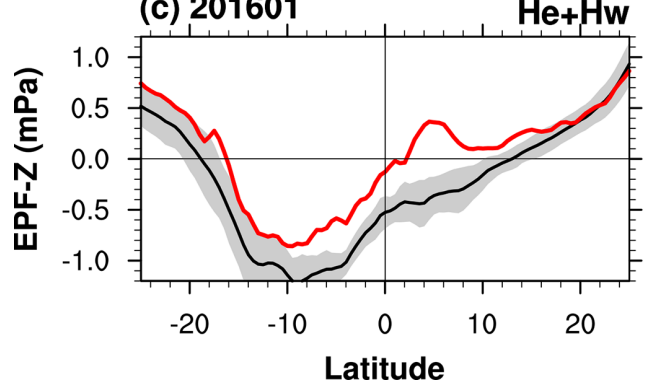

(b) 201512

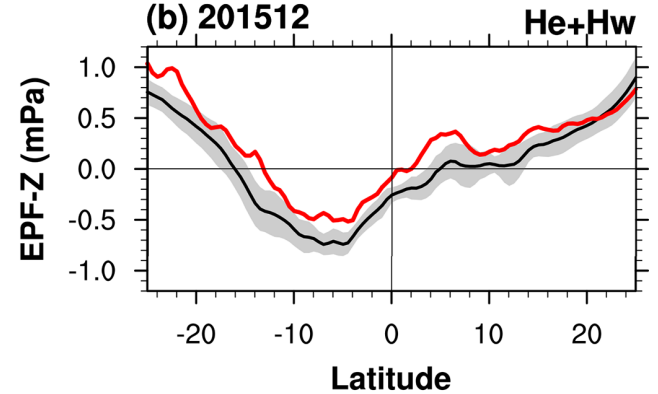

(d) 201602

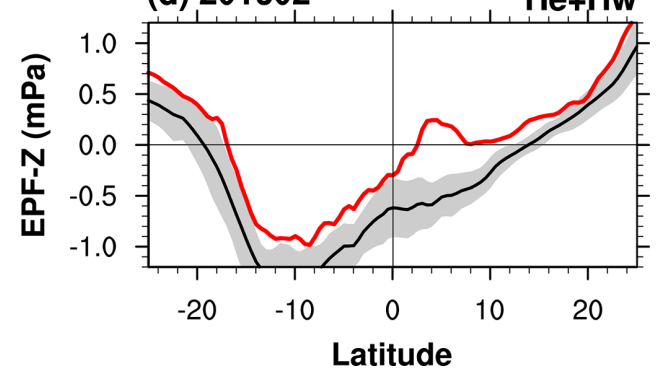

Figure 12. Vertical EP flux at $140 \mathrm{hPa}$ for the $H_{\mathrm{e}}+H_{\mathrm{w}}$ waves ((i) $|k|>20$ and $\omega>0$ cpd or (ii) $|k| \leq 20$ and $\omega>0.4$ cpd; approximately for the IG waves) in (a) November 2015, (b) December 2015, (c) January 2016, and (d) February 2016 (red) and their monthly climatology (black) with $\pm 1 \mathrm{SD}$ (gray shading).

\section{Precipitation spectrum (He,Hw)}
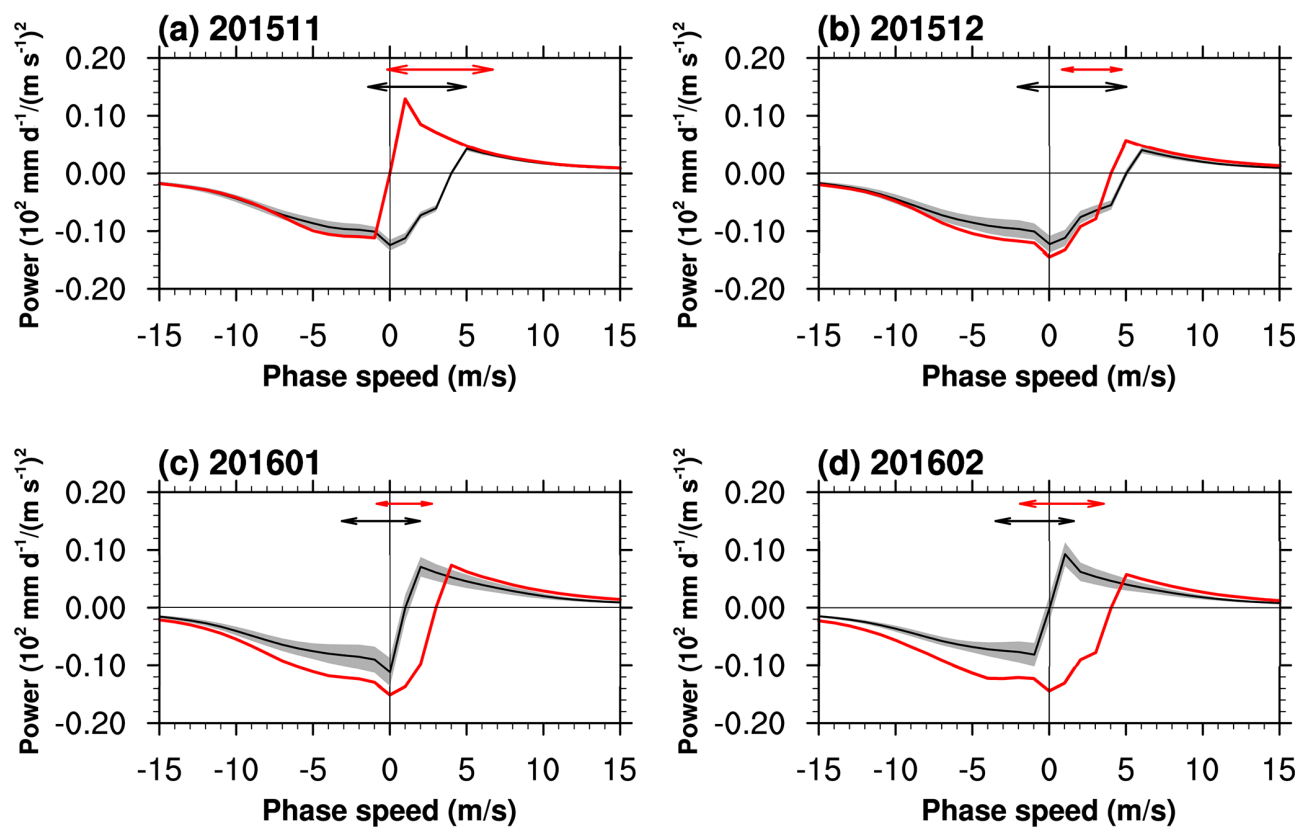

Figure 13. Phase-speed spectra of the precipitation in the spectral range of the $H_{\mathrm{e}}+H_{\mathrm{W}}$ waves ((i) $|k|>20$ and $\omega>0$ cpd or (ii) $|k| \leq 20$ and $\omega>0.4 \mathrm{cpd}$; approximately for the IG waves) averaged over $10^{\circ} \mathrm{N}-10^{\circ} \mathrm{S}$ in (a) November 2015, (b) December 2015, (c) January 2016 , and (d) February 2016, along with their monthly climatology (black) with \pm 1 SD (gray shading). Note that the power is multiplied by a negative sign when the phase speed is smaller than the zonal-mean zonal wind at $140 \mathrm{hPa}$ (i.e., source level). Double-sided arrows represent zonal wind ranges from 140 to $70 \mathrm{hPa}$ for the QBO disruption period (red) and the climatology (black). 

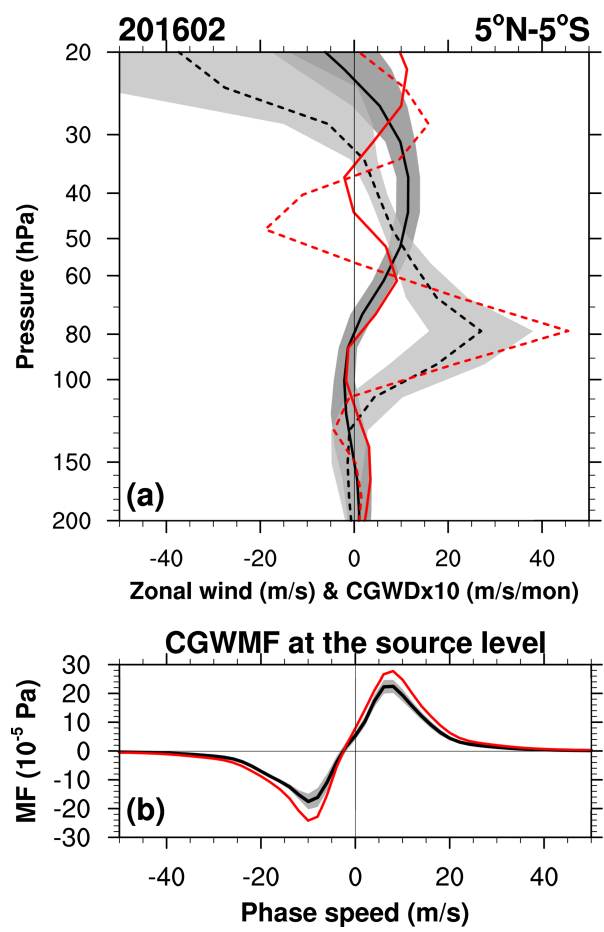

Figure 14. (a) The zonal-mean zonal wind profile and the zonal mean CGWD profile averaged over $5^{\circ} \mathrm{N}-5^{\circ} \mathrm{S}$ in February 2016 (red solid and red dashed, respectively) and those for the climatology (black solid and black dashed, respectively) with \pm 1 SD (dark gray and light gray shading, respectively). (b) Phase-speed spectra of the zonal-mean zonal CGW momentum flux at the source level averaged over $5^{\circ} \mathrm{N}-5^{\circ} \mathrm{S}$ in February 2016 (red) and the climatology (black) with $\pm 1 \mathrm{SD}$ (gray shading).

\subsection{Contribution of parameterized CGWs}

Figure 14 illustrates the zonal-mean zonal CGWD overlaid with the zonal-mean zonal wind profile and the source-level CGW momentum flux averaged over $5^{\circ} \mathrm{N}-5^{\circ} \mathrm{S}$ in February 2016, when CGWD started to contribute to the QBO disruption, along with the climatology. Negative CGWD appears where the vertical wind shear is negative, with a maximum magnitude of $-1.9 \mathrm{~m} \mathrm{~s}^{-1}$ per month at $47 \mathrm{hPa}$. Once a negative vertical wind shear develops, CGWs begin to exert negative forcing on the zonal wind, making the vertical wind shear stronger, which in turn leads to a greater negative CGWD. It is noticeable that the source-level CGW spectrum reveals much stronger momentum flux than the climatology, and the difference from the climatology is larger for the westward momentum flux than the eastward momentum flux, resulting in a faster and more irreversible easterly development at $40 \mathrm{hPa}$. In addition to the source spectrum, the apparent positive wind shear in the upper troposphere (140$200 \mathrm{hPa}$ ) during February 2016 enhances the propagation of westward waves into the stratosphere in comparison to the negative wind shear in the climatology.
We would like to answer the following two questions: (1) why is the source-level CGW momentum flux stronger in February 2016 than in the climatology? (2) Why is the increased amount of westward momentum flux larger than that of the eastward momentum flux? Figure 15 illustrates the convective source spectrum as well as the wave-filtering and resonance factor (WFRF) spectrum, which are two important factors constituting the source-level CGW momentum flux spectrum in the parameterization by Kang et al. (2017). The convective source spectrum is related to the size, magnitude, and movement of the convection: its magnitude is proportional to the square of the convective heating rate, having a peak where the phase speed equals the moving speed of convection $\left(c_{\mathrm{qh}}\right)$. WFRF is related to the shape of the wave spectra emitted from the convection, which includes two main effects: (i) critical-level filtering within the convective forcing region and (ii) the resonance between the vertical harmonics of the convective heating and the natural wave modes. As the convective heating is deeper, WFRF integrated over all phase speeds becomes larger and its peak is shifted to the higher phase speed (Song and Chun, 2005). The magnitude of the convective source spectrum (Fig. 15a) is much stronger than the climatology and WFRF (Fig. 15b) shows a stronger magnitude throughout all phase speeds, both of which lead to the exceptionally strong momentum flux of CGWs. The stronger magnitude of WFRF is not only due to the stronger and/or deeper convection caused by El Niño (Geller et al., 2016; Kawatani et al., 2019) but also due to the higher static stability at the cloud top $(\sim 200-300 \mathrm{hPa})$ in association with the warm surface temperature. Note that tropospheric static stability is enhanced under global warming (He et al., 2019; Richter et al., 2020), and 2016 is the warmest year on record for the global mean surface temperature (GISTEMP Team, 2020). The zonal wind at the cloud top (white line) exhibits a weaker easterly compared to the climatology: zonal winds at the cloud top averaged over $5^{\circ} \mathrm{N}-5^{\circ} \mathrm{S}$ are -3.4 and $-4.4 \mathrm{~m} \mathrm{~s}^{-1}$ for the disruption and the climatology, respectively. On the other hand, the difference in $c_{\mathrm{qh}}$ (gray line) is negligible. Thus, the westerly wind anomaly at the cloud top is responsible for the westward CGWs that are increased more than the eastward CGWs at the source level during the disruption.

\section{Summary and conclusion}

In this study, we have investigated the contribution of each equatorial planetary wave mode and parameterized convectively excited gravity waves, CGWs, to the 2015/16 QBO disruption by utilizing the equatorial wave separation method of Kim and Chun (2015a) and the offline CGW parameterization by Kang et al. (2017) with MERRA-2 model-level data. The main results, represented in schematic form in Fig. 16, are as follows. 
(a) Convective source
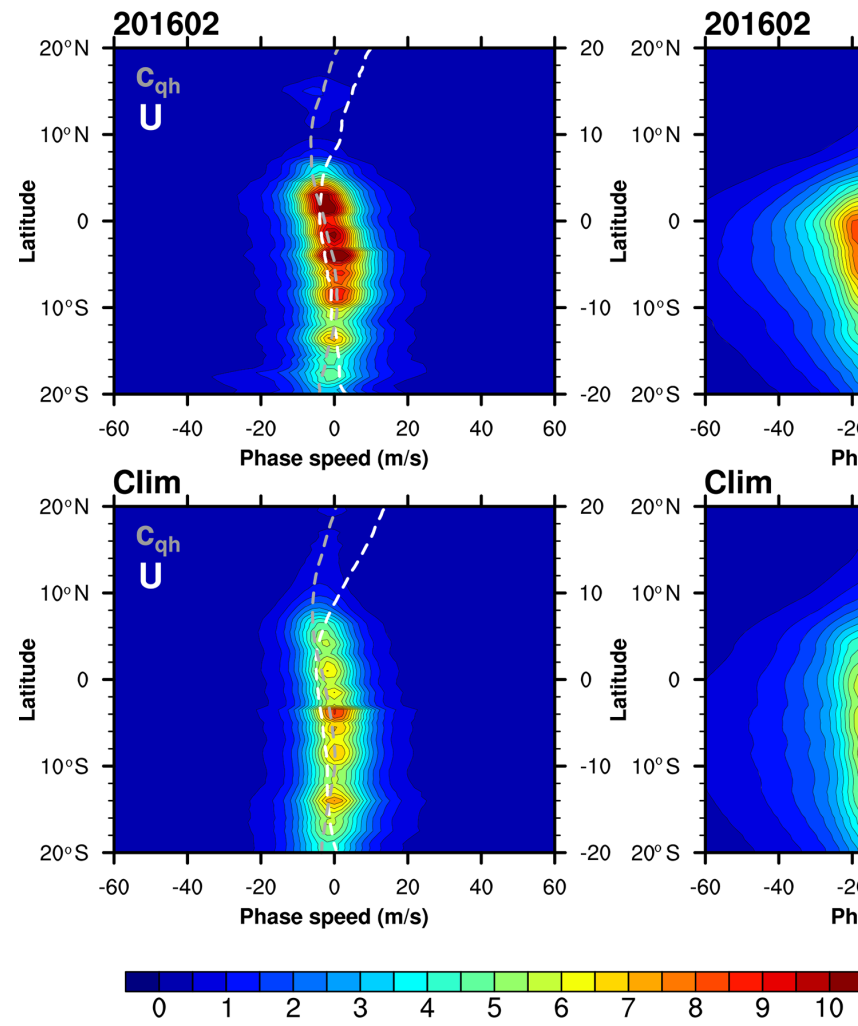

(b) WFRF

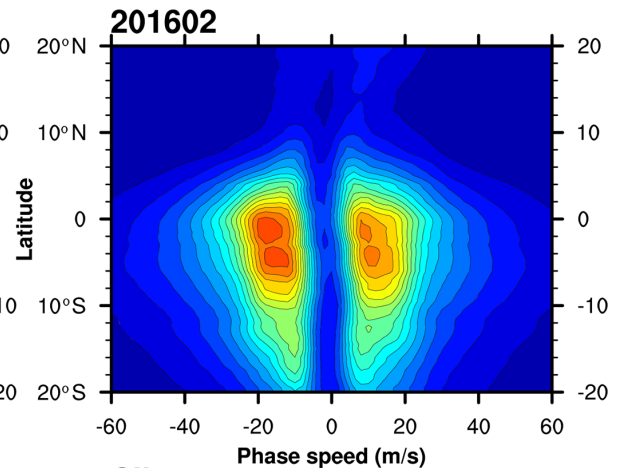

Clim

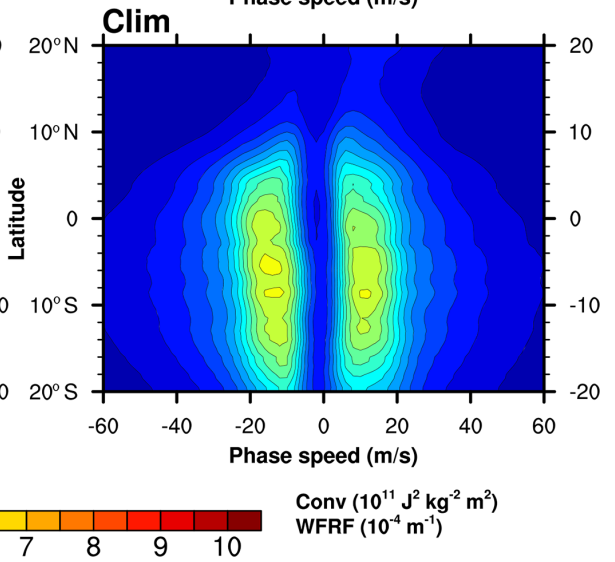

Figure 15. Latitudinal distributions of (a) the zonal mean convective source spectrum and (b) wave-filtering and resonance factor (WFRF) spectrum in (top) February 2016 and (bottom) the climatology. White and gray dashed lines in the convective source spectrum denote zonal-mean zonal wind $(U)$ and the moving speed of convection $\left(c_{\mathrm{qh}}\right)$, respectively.
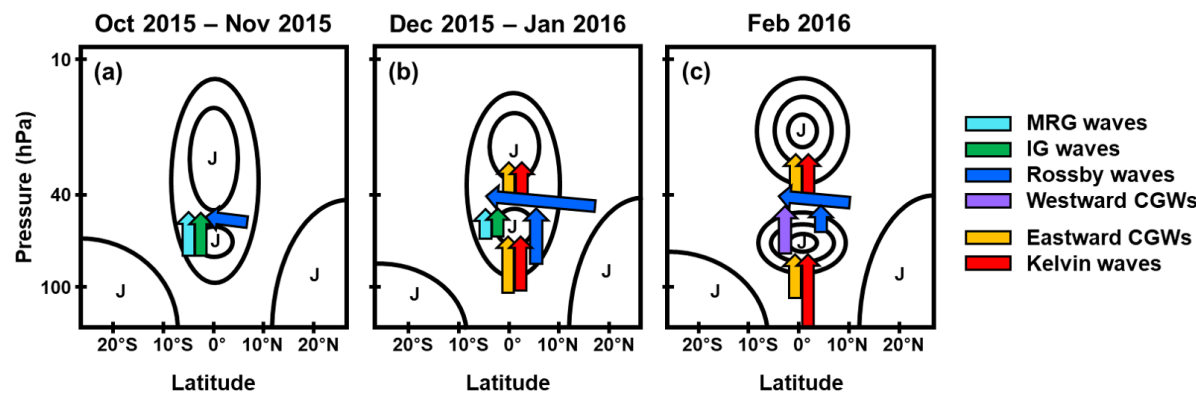

Figure 16. Schematic of the zonal wind evolution (black contour) and the anomalous wave forcing (arrow) during the QBO disruption in October-November 2015 (a), December 2015-January 2016 (b), and February 2016 (c). The "J" denotes a westerly jet.

- From October to November 2015, anomalously strong negative forcing by MRG waves mainly decelerated the QBO jet at $0-5^{\circ} \mathrm{S}$ near $40-50 \mathrm{hPa}$. From November 2015, IG wave forcing became anomalously strong at altitudes below $50 \mathrm{hPa}$, when the Rossby waves propagating from the $\mathrm{NH}$ began to break at the southern flank of the westerly jet $\left(0-10^{\circ} \mathrm{S}\right)$ at $30-60 \mathrm{hPa}$. The anomalous MRG waves were possibly generated by the increased frequency of barotropic instability in the lower stratosphere. IG wave forcing was attributed to (i) stronger convection in the equatorial troposphere, (ii) stronger westerly (or weaker easterly) winds leading to an enhanced westward momentum flux at the source level, and (iii) the reduced critical-level filtering of the westward waves arising from weaker negative wind shear in the UTLS compared to the climatology.

- From December 2015, Rossby wave breaking extends from the $\mathrm{SH}$ to the Equator. The deceleration of the QBO jet in the NH was mainly induced by the vertically propagating Rossby waves penetrating into the 
(a) EPD (EQ-5 $5^{\circ}$ )

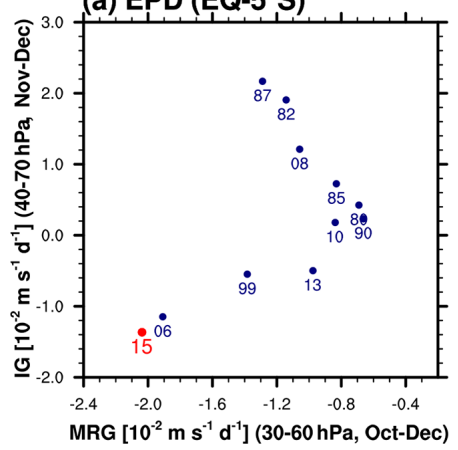

(b) EPF-Rossby (Jan-Feb)

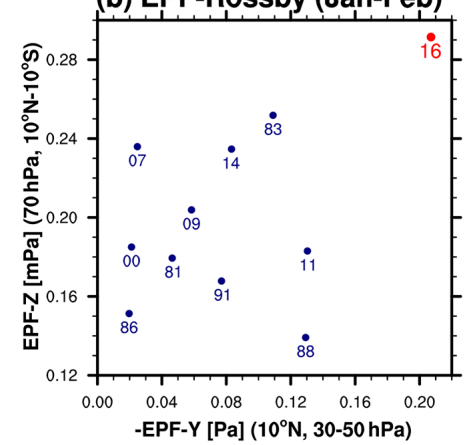

(c) CGWs (Feb, $\left.5^{\circ} \mathrm{N}-5^{\circ} \mathrm{S}\right)$

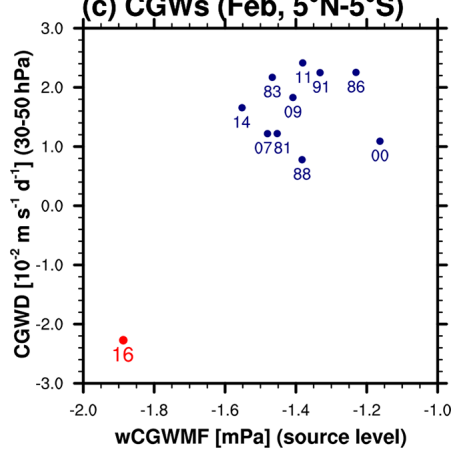

Figure 17. Scatter plots of the (a) EP flux divergence (EPD) for the MRG waves ( $x$ axis) and that for the IG waves $\left(y\right.$ axis) at $0-5^{\circ} \mathrm{S}$, averaged for October-December at 40-60 hPa and November-December at 30-70 hPa, respectively. (b) Meridional EPF (multiplied by -1 ) at $10^{\circ} \mathrm{N}$ and $30-50 \mathrm{hPa}\left(x\right.$ axis) and vertical $\mathrm{EPF}$ at $70 \mathrm{hPa}$ at $10^{\circ} \mathrm{N}-10^{\circ} \mathrm{S}$ ( $y$ axis) for the Rossby waves averaged for January-February. (c) Westward CGW momentum flux at the source level ( $x$ axis) and the zonal-mean zonal CGWD ( $y$ axis) at $30-50 \mathrm{hPa}$ at $5^{\circ} \mathrm{N}-5^{\circ} \mathrm{S}$ averaged for February. Red dots denote the disruption year (2015/16), and dark blue dots denote the other years with WQBO phases.

stratosphere. They likely originated in the $\mathrm{NH}$ and $\mathrm{SH}$ extratropics as well as in the tropics, generated by the convection in the equatorial troposphere. The deceleration of the QBO jet in the SH is mainly induced by Rossby waves propagating laterally from the $\mathrm{NH}$ extratropics. In January 2016, Rossby wave forcing was the strongest among all equatorial waves.

- In February 2016, the QBO jet at $40 \mathrm{hPa}$ was continuously decelerated by the Rossby waves, propagating both vertically and latitudinally. At the same time, the estimation of the CGW forcing suggests that CGWs provided negative forcing on the QBO jet at $40-50 \mathrm{hPa}$ near the Equator, contributing $20 \%$ of the total negative wave forcing. The enhancement in the negative CGWD is partly explained by an excessively strong westward momentum flux at the source level, which was attributed to the westerly wind anomaly at the source level and the reduced critical-level filtering of the westward waves in the upper troposphere.

- Meanwhile, the Kelvin waves and CGWs helped confine the development of the easterlies to the region near $40 \mathrm{hPa}$ by strengthening the westerly jets near $20-30$ and 60-80 hPa from January 2016.

In previous studies, laterally propagating Rossby waves from the midlatitudes have been considered the primary cause of the QBO disruption, although Lin et al. (2019) emphasized the role of local equatorial wave forcing in preconditioning the Rossby wave breaking. In the present study, we found that anomalously strong negative MRG and IG wave forcing in the early stage of the QBO disruption played a significant role in preconditioning the QBO jet core. Figure 17 shows scatter plots demonstrating how the wave flux or wave forcing was anomalously strong compared to the climatology. The negative EPDs for the MRG and IG waves in
2015 were the strongest among those in other WQBO cases (Fig. 17a), in which the EPDs for the MRG waves and IG waves are averaged for October-November and NovemberDecember, respectively. We also found that Rossby waves propagating upward from the equatorial troposphere significantly contribute to the QBO jet in the $\mathrm{NH}$, which helped to interrupt the westerly jet along with the equatorwardpropagating Rossby waves. Both the meridional and vertical EPF of the Rossby waves propagating into the equatorial stratosphere averaged for January-February in 2016 were stronger than those in any other years of WQBO phases (Fig. 17b). The contribution of the parameterized CGWs to the QBO disruption, which had been considered small, was found to be substantial when a physically based CGW parameterization was used; the negative CGWD in February 2016 was the largest among CGWD values in February with WQBO phases at $30-50 \mathrm{hPa}$ (Fig. 17c). The strongest CGWD at $30-50 \mathrm{hPa}$ is not surprising given that 2016 is the only year when the negative vertical wind shear occurs near $40 \mathrm{hPa}$ due to sudden easterly development. However, it is surprising that the westward CGW momentum flux at the source level in February 2016 was much stronger than in any other February with WQBO phases (Fig. 17c). This suggests that the variability of the GWs according to the convective activity leads to an enhancement in the negative CGWD at $40 \mathrm{hPa}$.

The current results are based on MERRA-2 data, and some uncertainties might be included in association with reanalysis data. Therefore, we checked whether the behavior of the equatorial waves in MERRA-2 also appears in ERA-I during the QBO disruption period (Figs. S5 and S6). The equatorial wave forcing in ERA-I showed a similar time evolution to that in MERRA-2, despite somewhat larger wave forcing in ERA-I. In addition, the tropical precipitation in MERRA2, which increased during the QBO disruption, was found to be evident in the observed precipitation (TRMM; Fig. S8). 
One additional point to mention about the uncertainties in our results is related to the cloud-top and cloud-bottom heights used for the CGW parameterization. Although we tried to make the vertical profiles of the convective heating rate comparable to those estimated from the satellite observations (Sect. 2.4), the CGW momentum flux spectrum is very sensitive to the cloud-top and cloud-bottom heights (Song and Chun, 2005; Kang et al., 2017) that are derived from the threshold percentage of the convective heating profiles. Considering the importance of cloud-top and cloud-bottom heights, their realistic estimation needs to be further investigated in the future.

Although not discussed in the Results section, a QBO westerly phase that does not rapidly propagate downward and maintains westerly winds throughout a deep layer might provide a favorable condition for QBO disruption. Hitchcock et al. (2018) mentioned that the westerly QBO should be deep enough to develop easterly winds away from the top and bottom shear regions of the jet. In addition, Osprey et al. (2016) reported enhanced tropical upwelling during the disruption. In our analysis, it is found that the mean upwelling $\left(\bar{w}^{*}\right)$ in the whole stratosphere was strengthened and upwelling in the upper stratosphere was stronger than the climatology (see the strong positive ADVz at the top of the QBO in Fig. 3), which made a deep and stalled QBO jet susceptible to continuous deceleration by wave forcing. Therefore, it would be interesting to investigate the vertical upwelling and its importance during the disruption period.

In this study, we found that the 2015/16 QBO disruption occurred when the following conditions were met: (i) negative equatorial wave (MRG, IG) forcing in the early stages and (ii) strong vertical and horizontal components of Rossby waves with strong small-scale CGWs in the later stages. The enhancement in convective activity and the anomalous wind profile, possibly attributed to a strong El Niño, lead to anomalously strong negative equatorial wave forcing. However, it is still puzzling why the equatorial wave activity in 2015/16 is stronger than that in other El Niño periods, which requires further investigation. Because more frequent occurrences of the QBO disruption are expected in a warmer climate (Osprey et al., 2016; Hirota et al., 2018), understanding the 2015/16 QBO disruption could eventually lead to an improvement of long-range forecasts in the future.

Data availability. The MERRA-2 data were provided by the Global Modeling and Assimilation Office at the NASA Goddard Space Flight Center through the NASA GES DISC online archive (available online at https://doi.org/10.5067/WWQSXQ8IVFW8, GMAO, 2015). The ERA-I data were obtained from the ECMWF data server (available online at http://apps.ecmwf.int/datasets/, 10 January 2020; ECMWF, 2009).
Supplement. The supplement related to this article is available online at: https://doi.org/10.5194/acp-20-14669-2020-supplement.

Author contributions. HYC and MJK designed the study, and MJK carried it out. MJK prepared the paper with contributions from $\mathrm{HYC}$ and RRG. All co-authors interpreted the results and reviewed and edited the paper.

Competing interests. The authors declare that they have no conflict of interest.

Acknowledgements. This work was supported by the National Research Foundation of Korea (NRF) through a grant funded by the Korean government (MSIT) (no. 2020R1A4A1016537). The authors thank the four anonymous reviewers and the editor for their careful reading of the paper and constructive comments. We would also like to thank Ji-Hee Yoo for helpful comments.

Financial support. This research has been supported by the National Research Foundation of Korea (NRF) through a grant funded by the Korean government (MSIT) (grant no. 2020R1A4A1016537).

Review statement. This paper was edited by Peter Haynes and reviewed by four anonymous referees.

\section{References}

Andrews, D. G. and Mcintyre, M. E.: Planetary waves in horizontal and vertical shear: The generalized Eliassen-Palm relation and the mean zonal acceleration, J. Atmos. Sci., 33, 2031-2048, 1976.

Andrews, D. G., Mahlman, J. D., and Sinclair, R. W.: EliassenPalm diagnostics of wave-mean flow interaction in the GFDL" SKYHI" general circulation model, J. Atmos. Sci., 40, 27682784, 1983.

Andrews, D. G., Holton, J. R., and Leovy, C. B.: Middle Atmosphere Dynamics, Academic, San Diego, California, 1987.

Anstey, J. A. and Shepherd, T. G.: High-latitude influence of the quasi-biennial oscillation, Q. J. Roy. Meteorol. Soc., 140, 1-21, https://doi.org/10.1002/qj.2132, 2014.

Baldwin, M. P. and Dunkerton, T. J.: Stratospheric harbingers of anomalous Weather Regimes, Science, 294, 581-584, 2001.

Baldwin, M. P., Gray, L. J., Dunkerton, T. J., Hamilton, K., Haynes, P. H., Randel, W. J., Holton, J. R., Alexander, M. J., Hirota, I., Horinouchi, T., Jones, D. B. A., Kinnersley, J. S., Marquardt, C., Sato, K., and Takahashi, M.: The quasi-biennial oscillation, Rev. Geophys., 39, 179-229, 2001.

Barton, C. A. and McCormack, J. P.: Origin of the 2016 QBO disruption and its relationship to extreme El Niño events, Geophys. Res. Lett., 44, 11150-11157, https://doi.org/10.1002/2017GL075576, 2017. 
Boer, G. and Hamilton, K.: QBO influence on extratropical predictive skill, Clim. Dynam., 31, 987-1000, https://doi.org/10.1007/s00382-008-0379-5, 2008.

Bosilovich, M. G., Lucchesi, R., and Suarez, M.: MERRA-2: File specification GMAO Office Note No. 9 (Version 1.1), available at: http://gmao.gsfc.nasa.gov/pubs/docs/Bosilovich785.pdf, last access: 20 June 2016.

Chao, W. C., Yang, B., and Fu, X.: A revised method of presenting wavenumber-frequency power spectrum diagrams that reveals the asymmetric nature of tropical large-scale waves, Clim. Dynam., 33, 843-847, https://doi.org/10.1007/s00382-008-0494-3, 2009.

Collimore, C. C., Martin, D. W., Hitchman, M. H., Huesmann, A., and Waliser, D. E.: On the relationship between the QBO and tropical deep convection, J. Climate, 16, 2552-2568, https://doi.org/10.1175/15200442(2003)016<2552:OTRBTQ>2.0.CO;2, 2003.

Coy, L., Newman, P. A., Pawson, S., and Lait, L. R.: Dynamics of the disrupted 2015/16 quasi-biennial oscillation, J. Climate, 30, 5661-5674, https://doi.org/10.1175/JCLI-D-16-0663.1, 2017.

Dee, D. P., Uppala, S. M., Simmons, A. J., Berrisford, P., Poli, P., Kobayashi, S., Andrae, U., Balmaseda, M. A., Balsamo, G., Bauer, P., Bechtold, P., Beljaars, A. C. M., van de Berg, L., Bidlot, J., Bormann, N., Delsol, C., Dragani, R., Fuentes, M., Geer, A. J., Haimberger, L., Healy, S. B., Hersbach, H., Hólm, E. V., Isaksen, L., Kållberg, P., Köhler, M., Matricardi, M., McNally, A. P., Monge-Sanz, B. M., Morcrette, J.-J., Park, B.-K., Peubey, C., de Rosnay, P., Tavolato, C., Thépaut, J.-N., and Vitart, F.: The ERA-Interim reanalysis: configuration and performance of the data assimilation system, Q. J. Roy. Meteorol. Soc., 137, 553597, https://doi.org/10.1002/qj.828, 2011.

Dunkerton, T. J.: Nonlinear propagation of zonal winds in an atmosphere with Newtonian cooling and equatorial wavedriving, J. Atmos. Sci., 48, 236-263, 1991.

Dunkerton, T. J.: The quasi-biennial oscillation of 2015-2016: Hiccup or death spiral?, Geophys. Res. Lett., 43, 10547-10552, https://doi.org/10.1002/2016GL070921, 2016.

ECMWF - European Centre for Medium-RangeWeather Forecasts: ERA Interim, 6-hourly, instantaneous, model-level, analysis, Reading, UK, ECMWF Meteorological Archival and Retrieval System (MARS), available at: https://apps.ecmwf.int/ datasets/data/interim-full-daily/levtype $=\mathrm{ml}$ (last access: $10 \mathrm{Jan}-$ uary 2020), 2009.

Ern, M., Ploeger, F., Preusse, P., Gille, J. C., Gray, L. J., Kalisch, S., Mlynczak, M. G., Russell III, J. M., and Riese, M.: Interaction of gravity waves with the QBO: A satellite perspective, J. Geophys. Res.-Atmos., 119, 2329-2355, https://doi.org/10.1002/2013JD020731, 2014.

Evan, S., Alexander, M. J., and Dudhia, J.: WRF simulations of convectively generated gravity waves in opposite QBO phases, J. Geophys. Res., 117, D12117, https://doi.org/10.1029/2011JD017302, 2012.

Garcia, R. R. and Richter, J. H.: On the momentum budget of the quasi-biennial oscillation in the Whole Atmosphere Community Climate Model, J. Atmos. Sci., 76, 69-87, https://doi.org/10.1175/JAS-D-18-0088.1, 2019.

Garfinkel, C. I. and Hartmann, D. L.: The influence of the quasibiennial oscillation on the troposphere in wintertime in a hierar- chy of models. Part I: Simplified dry GCMs, J. Atmos. Sci., 68, 1273-1289, 2011.

Gelaro, R., McCarty, W., Suarez, M. J., Todling, R., Molod, A., Takacs, L., Randles, C. A., Darmenov, A., Bosilovich, M. G., Reichle, R., Wargan, K., Coy, L., Cullather, R., Draper, C., Akella, S., Buchard, V., Conaty, A., da Silva, A. M., Gu, W., Kim, G.K., Koster, R., Lucchesi, R., Merkova, D., Nielsen, J. E., Partyka, G., Pawson, S., Putman, W., Rienecker, M., Schubert, S. D., Sienkiewicz, M., and Zhao, B.: The Modern-Era Retrospective Analysis for Research and Applications, Version 2 (MERRA-2), J. Climate, 30, 5419-5454, https://doi.org/10.1175/JCLI-D-160758.1, 2017.

Geller, M. A., Zhou, T., and Yuan, W.: The QBO, gravity waves forced by tropical convection, and ENSO, J. Geophys. Res.-Atmos., 121, 8886-8895, https://doi.org/10.1002/2015JD024125, 2016.

Gill, A. E.: Atmosphere-Ocean Dynamics, Academic Press, New York, 1982.

Giorgetta, M. A. and Bengtsson, L.: The potential role of the quasibiennial oscillation in the stratosphere-troposphere exchange as found in water vapor in general circulation model experiments, J. Geophys. Res., 104, 6003-6020, 1999.

GISTEMP Team: GISS Surface Temperature Analysis (GISTEMP), version 4, NASA Goddard Institute for Space Studies, Dataset, available at: https://data.giss.nasa.gov/gistemp/, last access: 10 September 2020.

GMAO: MERRA-2 inst3_3d_asm_Nv: 3D, 3-hourly, instantaneous, model-level, assimilation, assimilated meteorological fields, version 5.12.4, Goddard Earth Sciences Data and Information Services Center (GES DISC), Greenbelt, MD, USA, https://doi.org/10.5067/WWQSXQ8IVFW8, 2015.

GPM Science Team: GPM DPR (Gridded Convective Stratiform Heating) L3 1.5 hours 0.5 degree $\times 0.5$ degree V06, Goddard Earth Sciences Data and Information Services Center (GES DISC), https://doi.org/10.5067/GPM/DPRGMI/CSH/3G/06, 2017.

Gray, L. J., Anstey, J. A., Kawatani, Y., Lu, H., Osprey, S., and Schenzinger, V.: Surface impacts of the Quasi Biennial Oscillation, Atmos. Chem. Phys., 18, 8227-8247, https://doi.org/10.5194/acp-18-8227-2018, 2018.

Hamilton, K. P.: Mean wind evolution through the quasi-biennial cycle of the tropical lower stratosphere, J. Atmos. Sci., 41, 2113 2125, 1984.

He, C., Wang, Y., and Li, T.: Weakened impact of the developing El Niño on tropical Indian Ocean climate variability under global warming, J. Climate, 32, 7265-7279, https://doi.org/10.1175/JCLI-D-19-0165.1, 2019.

Hirota, N., Shiogama, H., Akiyoshi, H., Ogura, T., Takahashi, M., Kawatani, Y., Kimoto, M., and Mori, M.: The influences of El Nino and Arctic sea-ice on the QBO disruption in February 2016, Nat. Clim. Atmos. Sci., 1, 1-5, https://doi.org/10.1038/s41612-018-0020-1, 2018.

Hitchcock, P., Haynes, P. H., Randel, W. J., and Birner, T.: The emergence of shallow easterly jets within QBO westerlies, J. Atmos. Sci., 75, 21-40, https://doi.org/10.1175/JAS-D-17-0108.1, 2018.

Ho, C., Kim, H., Jeong, J. and Son, S.: Influence of stratospheric quasi-biennial oscillation on tropical cyclone tracks in 
the western North Pacific, Geophys. Res. Lett., 36, L06702, https://doi.org/10.1029/2009GL037163, 2009.

Holton, J. R. and Lindzen, R. S.: An updated theory for the quasi-biennial cycle of the tropical stratosphere, J. Atmos. Sci., 29, 1076-1080, https://doi.org/10.1175/15200469(1972)029<1076:AUTFTQ>2.0.CO;2, 1972.

Holton, J. R. and Tan, H.-C.: The influence of the equatorial quasi-biennial oscillation on global circulation at $50 \mathrm{mb}$, J. Atmos. Sci., 37, 2200-2208, https://doi.org/10.1175/15200469(1980)037<2200:TIOTEQ>2.0.CO;2, 1980.

Horinouchi, T., Pawson, S., Shibata, K., Manzini, E., Giorgetta, M., and Sassi, F.: Tropical cumulus convection and upward propagating waves in middle-atmospheric GCMs, J. Atmos. Sci., 60, 2765-2782, 2003.

Huffman, G., Bolvin, D., Braithwaite, D., Hsu, K., Joyce, R., and Xie, P.: Integrated Multi-satellite Retrievals for GPM (IMERG), version 4.4, NASA's Precipitation Processing Center, available at: ftp://arthurhou.pps.eosdis.nasa.gov/gpmdata/ (last access: 31 March 2015), 2014.

Jewtoukoff, V., Plougonven, R., and Hertzog, A.: Gravity waves generated by deep tropical convection: Estimates from balloon observations and mesoscale simulations, J. Geophys. Res.Atmos., 118, 9690-9707, https://doi.org/10.1002/jgrd.50781, 2013.

Kang, M.-J., Chun, H.-Y., and Kim, Y.-H.: Momentum flux of convective gravity waves derived from an offline gravity wave parameterization. Part I: Spatiotemporal variations at source level, J. Atmos. Sci., 74, 3167-3189, https://doi.org/10.1175/JAS-D17-0053.1, 2017.

Kang, M.-J., Chun, H.-Y., Kim, Y.-H., Preusse, P., and Ern, M.: Momentum flux of convective gravity waves derived from an offline gravity wave parameterization. Part II: Impacts on the quasi-biennial oscillation, J. Atmos. Sci., 75, 3753-3775, https://doi.org/10.1175/JAS-D-18-0094.1, 2018.

Kawatani, Y., Watanabe, S., Sato, K., Dunkerton, T. J., Miyahara, S., and Takahashi, M.: The roles of equatorial trapped waves and internal inertia-gravity waves in driving the quasi-biennial oscillation. Part I: Zonal mean wave forcing, J. Atmos. Sci., 67, 963-980, https://doi.org/10.1175/2009JAS3222.1, 2010.

Kawatani, Y., Hamilton, K., Sato, K., Dunkerton, T. J., Watanabe, S., and Kikuchi, K.: ENSO modulation of the QBO: Results from MIROC models with and without nonorographic gravity wave parameterization, J. Atmos. Sci., 76, 3893-3917, 2019.

Kidston, J., Scaife, A. A., Hardiman, S. C., Mitchell, D. M., Butchart, N., Baldwin, M. P., and Gray, L. J.: Stratospheric influence on tropospheric jet streams, storm tracks and surface weather, Nat. Geosci., 8, 433-440, 2015.

Kim, Y.-H. and Chun, H.-Y.: Contributions of equatorial wave modes and parameterized gravity waves to the tropical QBO in HadGEM2, J. Geophys. Res.-Atmos., 120, 1065-1090, https://doi.org/10.1002/2014JD022174, 2015a.

Kim, Y.-H. and Chun, H.-Y.: Momentum forcing of the quasibiennial oscillation by equatorial waves in recent reanalyses, Atmos. Chem. Phys., 15, 6577-6587, https://doi.org/10.5194/acp15-6577-2015, $2015 b$.

Kim, Y.-H., Kiladis, G. N., Albers, J. R., Dias, J., Fujiwara, M., Anstey, J. A., Song, I.-S., Wright, C. J., Kawatani, Y., Lott, F., and Yoo, C.: Comparison of equatorial wave activity in the tropical tropopause layer and stratosphere repre- sented in reanalyses, Atmos. Chem. Phys., 19, 10027-10050, https://doi.org/10.5194/acp-19-10027-2019, 2019.

Kumar, K. K., Mathew, S. S., and Subrahmanyam, K. V.: Anomalous tropical planetary wave activity during 2015/2016 quasi biennial oscillation disruption, J. Atmos. Sol.-Ter. Phy., 167, 184189, https://doi.org/10.1016/j.jastp.2017.12.004, 2018.

Lang, S. E. and Tao, W.-K.: The next-generation Goddard convective-stratiform heating algorithm: New tropical and warmseason retrievals for GPM, J. Climate, 31, 5997-6026, 2018.

Lee, J.-H., Kang, M.-J., and Chun, H.-Y.: Differences in the tropical convective activities at the opposite phases of the quasi-biennial oscillation, Asia-Pac. J. Atmos. Sci., 55, 317-336, 2019.

Li, H., Pilch Kedzierski, R., and Matthes, K.: On the forcings of the unusual Quasi-Biennial Oscillation structure in February 2016, Atmos. Chem. Phys., 20, 6541-6561, https://doi.org/10.5194/acp-20-6541-2020, 2020.

Liess, S. and Geller, M. A.: On the relationship between QBO and distribution of tropical deep convection, J. Geophys. Res., 117, D03108, https://doi.org/10.1029/2011JD016317, 2012.

Lin, P., Held, I., and Ming, Y.: The early development of the 2015/16 quasi-biennial oscillation disruption, J. Atmos. Sci., 76, 821-836, https://doi.org/10.1175/JAS-D-18-0292.1, 2019.

Lindzen, R. S.: Turbulence and stress owing to gravity wave and tidal breakdown, J. Geophys. Res., 86, 9707-9714, https://doi.org/10.1029/JC086iC10p09707, 1981.

Lindzen, R. S. and Holton, J. R.: A theory of the quasi-biennial oscillation, J. Atmos. Sci., 25, 1095-1107, https://doi.org/10.1175/15200469(1968)025<1095:ATOTQB>2.0.CO;2, 1968.

Marshall, A. G., Hendon, H. H., Son, S.-W., and Lim, Y.: Impact of the quasi-biennial oscillation on predictability of the Madden-Julian oscillation, Clim. Dynam., 49, 1365-1377, https://doi.org/10.1007/s00382-016-3392-0, 2017.

Newman, P. A., Coy, L., Pawson, S. and Lait, L. R.: The anomalous change in the QBO in 2015-2016, Geophys. Res. Lett., 43, 8791-8797, https://doi.org/10.1002/2016GL070373, 2016.

Osprey, S. M., Butchart, N., Knight, J. R., Scaife, A. A., Hamilton, K., Anstey, J. A., Schenzinger, V., and Zhang, C.: An unexpected disruption of the atmospheric quasi-biennial oscillation, Science, 353, 1424-1427, https://doi.org/10.1126/science.aah4156, 2016.

O'Sullivan, D.: Interaction of extratropical Rossby waves with westerly quasi-biennial oscillation winds, J. Geophys. Res., 102, 19461-19469, https://doi.org/10.1029/97JD01524, 1997.

Patra, P. K., Lal, S., Venkataramani, S., and Chand, D.: Halogen Occultation Experiment (HALOE) and balloon-borne in situ measurements of methane in stratosphere and their relation to the quasi-biennial oscillation (QBO), Atmos. Chem. Phys., 3, 10511062, https://doi.org/10.5194/acp-3-1051-2003, 2003.

Randel, W. J. and Wu, F.: Isolation of the ozone QBO in SAGE II data by singular-value decomposition, J. Atmos. Sci., 53, 25462559, 1996.

Richter, J. H., Solomon, A., and Bacmeister, J. T.: On the simulation of the quasi-biennial oscillation in the Community Atmosphere Model, version 5, J. Geophys. Res.-Atmos., 119, 30453062, https://doi.org/10.1002/2013JD021122, 2014.

Richter, J. H., Butchart, N., Kawatani, Y., Bushell, A. C., Holt, L., Serva., F., Anstey, J., Simipson, I. R., Osprey, S., Hamilton, K., Braesicke, P., Cagnazzo, C., Chen, C.-C., Garcia, R. R., Gray, L. J., Kerzenmacher, T., Lott, F., McLandress, C., Naoe, H., 
Scinocca, J., Stockdale, T. N., Versick, S., Watanabe. S., Yoshida, K., and Yukimoto, S.: Response of the quasi-biennial oscillation to a warming climate in global climate models, Q. J. Roy. Meteorol. Soc., 1-29, https://doi.org/10.1002/qj.3749, 2020.

Saha, S., Moorthi, S., Pan, H.-L., Wu, X., Wang, J., Nadiga, S., Tripp, P., Kistler, R., Woollen, J., Behringer, D., Liu, H., Stokes, D., Grumbine, R., Gayno, G., Wang, J., Hou, Y.-T., Chuang, H.Y., Juang, H.-M. H., Sela, J., Iredell, M., Treadon, R., Kleist, D., Van Delst, P., Keyser, D., Derber, J., Ek, M., Meng, J., Wei, H., Yang, R., Lord, S., van den Dool, H., Kumar, A., Wang, W., Long, C., Chelliah, M., Xue, Y., Huang, B., Schemm, J.-K., Ebisuzaki, W., Lin, R., Xie, P., Chen, M., Zhou, S., Higgins, W., Zou, C.-Z., Liu, Q., Chen, Y., Han, Y., Cucurull, L., Reynolds, R. W., Rutledge, G., and Goldberg, M.: The NCEP Climate Forecast System Reanalysis, B. Am. Meteorol. Soc., 91, 1015-1057, 2010

Scaife, A. A., Athanassiadou, M., Andrews, M., Arribas, A., Baldwin, M., Dunstone, N., Knight, J., MacLachlan, C., Manzini, E., Müller, W. A., Pohlmann, H., Smith, D., Stockdale, T., and Williams, A.: Predictability of the quasi-biennial oscillation and its northern winter teleconnection on seasonal to decadal timescales, Geophys. Res. Lett., 41, 1752-1758, 2014.
Song, I.-S. and Chun, H.-Y.: Momentum flux spectrum of convectively forced internal gravity waves and its application to gravity wave drag parameterization. Part I: Theory, J. Atmos. Sci., 62, 107-124, https://doi.org/10.1175/JAS-3363.1, 2005.

Watanabe, S. and Miyahara, S.: Quantification of the gravity wave forcing of the migrating diurnal tide in a gravity wave-resolving general circulation model, J. Geophys. Res., 114, D07110, https://doi.org/10.1029/2008JD011218, 2009.

Watanabe, S., Hamilton, K., Osprey, S., Kawatani, Y., and Nishimoto, E.: First successful hindcast of the 2016 disruption of the stratospheric quasi-biennial oscillation, Geophys. Res. Lett., 45, 1602-1610, https://doi.org/10.1002/2017GL076406, 2018.

Wheeler, M. and Kiladis, G. N.: Convectively coupled equatorial waves: Analysis of clouds and temperature in the wavenumberfrequency domain, J. Atmos. Sci., 56, 374-399, 1999.

Yang, G., Hoskins, B., and Slingo, J.: Equatorial waves in opposite QBO phases, J. Atmos. Sci., 68, 839-862, https://doi.org/10.1175/2010JAS3514.1, 2011.

Yoo, C. and Son, S.-W.: Modulation of the boreal wintertime Madden-Julian oscillation by the stratospheric quasibiennial oscillation, Geophys. Res. Lett., 43, 1392-1398, https://doi.org/10.1002/2016GL067762, 2016. 